\title{
The gut bacterial community potentiates Clostridioides 2 difficile infection severity.
}

3 Running title: Microbiota potentiates Clostridioides difficile infection severity

4 Nicholas A. Lesniak ${ }^{1}$, Alyxandria M. Schubert ${ }^{1}$, Kaitlyn J. Flynn ${ }^{1}$, Jhansi L. Leslie ${ }^{1,4}$, 5 Hamide Sinani ${ }^{1}$, Ingrid L. Bergin ${ }^{3}$, Vincent B. Young ${ }^{1,2}$, Patrick D. Schloss ${ }^{1, \dagger}$

6 † To whom correspondence should be addressed: pschloss@umich.edu

7 1. Department of Microbiology and Immunology, University of Michigan, Ann Arbor, MI 2. Division of Infectious Diseases, Department of Internal Medicine, University of Michigan Medical School, Ann Arbor, MI 3. Unit for Laboratory Animal Medicine, University of Michigan, Ann Arbor, MI

4. Current affiliation: Department of Medicine, Division of International Health and Infectious Diseases, University of Virginia School of Medicine, Charlottesville, Virginia, USA 


\section{Abstract}

The severity of Clostridioides difficile infections (CDI) has increased over the last few decades. Patient age, white blood cell count, creatinine levels as well as $C$. difficile ribotype and toxin genes have been associated with disease severity. However, it is unclear whether there is an association between members of the gut microbiota and disease severity. The gut microbiota is known to interact with $C$. difficile during infection. Perturbations to the gut microbiota are necessary for $C$. difficile to colonize the gut. The gut microbiota can inhibit $C$. difficile colonization through bile acid metabolism, nutrient consumption and bacteriocin production. Here we sought to demonstrate that members of the gut bacterial communities can also contribute to disease severity. We derived diverse gut communities by colonizing germ-free mice with different human fecal communities. The mice were then infected with a single $C$. difficile ribotype 027 clinical isolate which resulted in moribundity and histopathologic differences. The variation in severity was associated with the human fecal community that the mice received. Generally, bacterial populations with pathogenic potential, such as Escherichia, Helicobacter, and Klebsiella, were associated with more severe outcomes. Bacterial groups associated with fiber degradation, bile acid metabolism and lantibiotic production, such as Anaerostipes and Coprobacillus, were associated with less severe outcomes. These data indicate that, in addition to the host and C. difficile, populations of gut bacteria can influence CDI disease severity.

\section{Importance}

Clostridioides difficile colonization can be asymptomatic or develop into an infection, ranging in severity from mild diarrhea to toxic megacolon, sepsis, and death. Models that predict severity and guide treatment decisions are based on clinical factors and $C$. difficile characteristics. Although the gut microbiome plays a role in protecting against CDI, its effect on CDI disease severity is unclear and has not been incorporated into disease 
severity models. We demonstrated that variation in the microbiome of mice colonized with human feces yielded a range of disease outcomes. These results revealed groups of bacteria associated with both severe and mild $C$. difficile infection outcomes. Gut bacterial community data from patients with CDI could improve our ability to identify patients at risk of developing more severe disease and improve interventions which target $C$. difficile and the gut bacteria to reduce host damage. 


\section{Introduction}

Clostridioides difficile infections (CDI) have increased in incidence and severity since $C$. difficile was first identified as the cause of antibiotic-associated pseudomembranous colitis (1). CDI disease severity can range from mild diarrhea to toxic megacolon and death. The Infectious Diseases Society of America (IDSA) and Society for Healthcare Epidemiology of America (SHEA) guidelines define severe CDI in terms of a white blood cell count greater than 15,000 cells $/ \mathrm{mm}^{3}$ and/or a serum creatinine greater than $1.5 \mathrm{mg} / \mathrm{dL}$. Patients who develop shock or hypotension, ileus, or toxic megacolon are considered to have fulminant CDI (2). Since these measures are CDI outcomes, they have limited ability to predict risk of severe CDI when the infection is first detected. Schemes have been developed to score a patient's risk for severe CDI outcomes based on clinical factors but have not been robust for broad application (3). Thus, we have limited ability to prevent patients from developing severe CDI.

Missing from CDI severity prediction models are the effects of the indigenous gut bacteria. C. difficile interacts with the gut community in many ways. The indigenous bacteria of a healthy intestinal community provide a protective barrier preventing $C$. difficile from infecting the gut. A range of mechanisms can disrupt this barrier, including antibiotics, medications, or dietary changes, and lead to increased susceptibility to CDI (4-6). Once C. difficile overcomes the protective barrier and colonizes the intestine, the indigenous bacteria can either promote or inhibit $C$. difficile through producing molecules or modifying the environment $(7,8)$. Bile acids metabolized by the gut bacteria can inhibit $C$. difficile growth and affect toxin production $(9,10)$. Bacteria in the gut also can compete more directly with $C$. difficile through antibiotic production or nutrient consumption (11-13). While the relationship between the gut bacteria and $C$. difficile has been established, the effect the gut bacteria can have on CDI disease severity is unclear.

Recent studies have demonstrated that when mice with diverse microbial communities 
were challenged with a high-toxigenic strain resulted in varied disease severity (14) and when challenged with a low-toxigenic strain members of the gut microbial community associated with variation in colonization (15). Here, we sought to further elucidate the relationship between members of the gut bacterial community and CDI disease severity when challenged with a high-toxigenic strain, C. difficile ribotype 027 (RT027). We hypothesized that since specific groups of gut bacteria affect the metabolism of $C$. difficile and its infection dynamics, we can also identify groups of bacteria that affect the disease severity of the infection. To test this hypothesis, we colonized germ-free C57BL/6 mice with human fecal samples to create varied gut communities. We then challenged the mice with C. difficile RT027 and followed the mice for the development of severe outcomes of moribundity and histopathologic cecal tissue damage. Since the murine host and $C$. difficile isolate were the same and only the gut community varied, the variation in disease severity we observed was attributable to the gut microbiome.

\section{Results}

\section{C. difficile is able to infect germ-free mice colonized with human fecal microbial} communities without antibiotics. To produce gut microbiomes with greater variation than those found in conventional mouse colonies, we colonized germ-free mice with bacteria from human feces (16). We inoculated germ-free C57BL/6 mice with homogenized feces from each of 15 human fecal samples via oral gavage. These human fecal samples were selected because they represented diverse community structures based on community clustering (17). The gut communities were allowed to equilibrate for two weeks post-inoculation (18). We then surveyed the bacterial members of the gut communities by 16S rRNA gene sequencing of murine fecal pellets (Figure 1A). The bacterial communities from each mouse grouped more closely to those communities from mice that received the same human fecal donor community than to the mice who received a different human fecal donor community (Figure 1B). The communities were primarily composed of populations 
of Clostridia, Bacteroidia, Erysipelotrichia, Bacilli, and Gammaproteobacteria. However, the gut bacterial communities of each donor group of mice harbored unique relative abundance distributions of the shared bacterial classes.

Next, we tested this set of mice with their human-derived gut microbial communities for susceptibility to $C$. difficile infection. A typical mouse model of $C D I$ requires pre-treatment of conventional mice with antibiotics, such as clindamycin, to become susceptible to $C$. difficile colonization $(19,20)$. However, we wanted to avoid modifying the gut communities with an antibiotic to maintain their unique microbial compositions and ecological relationships. Since some of these communities came from people at increased risk of CDI, such as recent hospitalization or antibiotic use (17), we tested whether $C$. difficile was able to infect these mice without an antibiotic perturbation. We hypothesized that $C$. difficile would be able to colonize the mice who received their gut communities from a donor with a perturbed community. Mice were challenged with $10^{3} \mathrm{C}$. difficile RT027 clinical isolate spores. The mice were followed for 10 days post-challenge, and their stool was collected and plated for C. difficile colony forming units (CFU) to determine the extent of the infection. Surprisingly, communities from all donors were able to be colonized (Figure 2). Two mice were able to resist $C$. difficile colonization, both received their community donor $\mathrm{N} 1$, which may be attributed to experimental variation since this group also had more mice. By colonizing germ-free mice with different human fecal communities, we were able to generate diverse gut communities in mice, which were susceptible to $C$. difficile infection without further modification of the gut community.

Infection severity varies by initial community. After we challenged the mice with $C$. difficile, we investigated the outcome from the infection and its relationship to the initial community. We followed the mice for 10 days post-challenge for colonization density, toxin production, and mortality. Seven mice, from Donors N1, N3, N4, and N5, were not colonized at detectable levels on the day after $C$. difficile challenge but were infected 
$\left(>10^{6}\right)$ by the end of the experiment. All mice that received their community from Donor M1 through M6 succumbed to the infection and became moribund within 3 days post-challenge. The remaining mice, except the uninfected Donor N1 mice, maintained $C$. difficile infection through the end of the experiment (Figure 2). At 10 days post-challenge, or earlier for the moribund mice, mice were euthanised and fecal material were assayed for toxin activity and cecal tissue was collected and scored for histopathologic signs of disease (Figure 3). Overall, there was greater toxin activity detected in the stool of the moribund mice $(P=$ 0.003). However, when looking at each group of mice, we observed a range in toxin activity for both the moribund and non-moribund mice (Figure 3A). Non-moribund mice from Donors $\mathrm{N} 2$ and N5 through N9 had comparable toxin activity as the moribund mice. Additionally, not all moribund mice had toxin activity detected in their stool. Next, we examined the cecal tissue for histopathologic damage. Moribund mice had high levels of epithelial damage, tissue edema, and inflammation (Figure S1) similar to previously reported histopathologic findings for $C$. difficile RT027 (21). As observed with toxin activity, the moribund mice had higher histopathologic scores than the non-moribund mice $(P<0.001)$. However, unlike the toxin activity, all moribund mice had consistently high histopathologic summary scores (Figure 3B). The non-moribund mice, Donor groups N1 through N9, had a range in tissue damage from none detected to similar levels as the moribund mice, which grouped by community donor. Together, the toxin activity, histopathologic score, and moribundity showed variation across the donor groups but were largely consistent within each donor group.

Microbial community members explain variation in CDI severity. We next interrogated the bacterial communities at the time of $C$. difficile challenge (day 0 ) for their relationship to infection outcomes using linear discriminant analysis (LDA) effect size (LEfSe) analysis to identify individual bacterial populations that could explain the variation in disease severity. We split the mice into groups by severity level based on their moribundity and histopathologic score. We dichotomized the histopathologic scores 
into high and low groups by splitting on the median score of 5 . This analysis revealed 20 genera that were significantly different by the disease severity (Figure $4 A$ ). Bacterial genera Turicibacter, Streptococcus, Staphylococcus, Pseudomonas, Phocaeicola, Parabacteroides, Bacteroides, and Escherichia/Shigella were detected at higher relative abundances in the mice that became moribund. Populations of Anaerotignum, Coprobacillus, Enterocloster, and Murimonas were more abundant in the non-moribund mice that would develop only low intestinal injury. To understand the role of toxin activity in disease severity, we applied LEfSe to identify the genera most likely to explain the differences between the presence and absence of detected toxin activity (Figure 4B). Many genera that associated with the presence of toxin were also associated with moribundity, such as populations of Escherichia/Shigella and Bacteroides. Likewise, there were genera such as Anaerotignum, Enterocloster, and Murimonas that were associated with no detected toxin that also exhibited greater relative abundance in communities from non-moribund mice with a low histopathologic score. Lastly, we tested for correlations between the endpoint relative abundances of bacterial operational taxonomic units (OTUs) and the histopathologic summary score (Figure 4C). The endpoint relative abundance of Bacteroides was positively correlated with histopathologic score, as its day 0 relative abundance did with disease severity (Figure 4A). Populations of Klebsiella and Prevotellaceae were positively correlated with the histopathologic score and were increased in the group of mice with detectable toxin. This analysis identified bacterial genera that were associated with the variation in moribundity, histopathologic score, and toxin.

We next determined whether, collectively, bacterial community membership and relative abundance could be predictive of the CDI disease outcome. We trained random forest models with bacterial community relative abundance data from the day of colonization at each taxonomic rank to predict toxin, moribundity, and day 10 post-challenge histopathologic summary score. For predicting if detectable toxin would be produced, 
microbial populations aggregated by phylum rank classification performed similarly as models using lower taxonomic ranks $(A \cup R O C=0.83$, Figure $S 2)$. C. difficile was more likely to produce detectable toxin when the community infected had less abundant populations of Verrucomicrobia and Campilobacterota and had more abundant populations of Proteobacteria (Figure 5A). Next, we assessed the ability of the community to predict moribundity. Bacteria grouped by class rank classification was sufficient to predict which mice would succumb to the infection before the end of the experiment (AUROC $=0.91$, Figure S2). The features with the greatest effect showed that communities with greater populations of bacteria belonging to Bacilli and Firmicutes and reduced populations of Erysipelotrichia were more likely to result in moribundity (Figure 5B). Only one other class of bacteria was decreased in moribund mice, a group of unclassified Clostridia. Lastly, the relative abundances of genera were able to predict a high or low histopathologic score (histopathologic scores were dichotomized as in previous analysis, AUROC $=0.99$, Figure S2). No genera had a significantly greater effect on the model performance than any others, indicating the model was reliant on many genera for the correct prediction. The model used some of the genera identified in the LEfSe analysis, such as Coprobacillus, Anaerostipes, and Hungatella. Communities with greater abundances of Hungatella, Eggerthella, Bifidobacterium, Duncaniella and Neisseria were more likely to have high histopathologic scores. These models have shown that the relative abundance of bacterial populations and their relationship to each other could be used to predict the variation in moribundity, histopathologic score, and detectable toxin of CDI.

\section{Discussion}

Challenging mice colonized with different human fecal communities with C. difficile RT027 demonstrated that variation in members of the gut microbiome affects $C$. difficile infection disease severity. Our analysis revealed an association between the relative abundance of bacterial community members and disease severity. Previous studies investigating the 
severity of CDI disease involving the microbiome have had limited ability to interrogate this relationship between the microbiome and disease severity. Studies that have used clinical data have limited ability to control variation in the host, microbiome or $C$. difficile ribotype (22). Murine experiments typically use a single mouse colony and different $C$. difficile ribotypes to create severity differences (23). Recently, our group has begun uncovering the effect microbiome variation has on $C$. difficile infection. We showed the variation in the bacterial communities between mice from different mouse colonies resulted in different clearance rates of $C$. difficile (15). We also showed varied ability of mice to spontaneously eliminate $C$. difficile infection when they were treated with different antibiotics prior to $C$. difficile challenge (24). Overall, the results presented here have demonstrated that the gut bacterial community contributed to the severity of $C$. difficile infection.

C. difficile can lead to asymptomatic colonization or infections with severity ranging from mild diarrhea to death. Physicians use classification tools to identify patients most at risk of developing a severe infection using white blood cell counts, serum albumin level, or serum creatinine level $(2,25,26)$. Those levels are driven by the activities in the intestine (27). Research into the drivers of this variation have revealed factors that make $C$. difficile more virulent. Strains are categorized for their virulence by the presence and production of the toxins TcdA, TcdB, and binary toxin and the prevalence in outbreaks, such as ribotypes 027 and $078(19,28-31)$. However, other studies have shown that disease is not necessarily linked with toxin production (32) or the strain (33). Furthermore, there is variation in the genome, growth rate, sporulation, germination, and toxin production in different isolates of a strain (34-37). This variation may help explain why severe CDI prediction tools often miss identifying many patients with $C D I$ that will develop severe disease $(3,23,38,39)$. Therefore, it is necessary to gain a full understanding of all factors contributing to disease variation to improve our ability to predict severity.

The state of the gut bacterial community determines the ability of $C$. difficile to colonize 
and persist in the intestine. C. difficile is unable to colonize an unperturbed healthy murine gut community and is only able to become established after a perturbation (20). Once colonized, the different communities lead to different metabolic responses and dynamics of the $C$. difficile population $(8,24,40)$. Gut bacteria metabolize primary bile acids into secondary bile acids $(41,42)$. The concentration of these bile acids affects germination, growth, toxin production and biofilm formation $(9,10,43,44)$. Members of the bacterial community also affect other metabolites $C$. difficile utilizes. Bacteroides thetaiotaomicron produce sialidases which release sialic acid from the mucosa for $C$. difficile to utilize (45, 46). The nutrient environment affects toxin production (47). Thus, many of the actions of the gut bacteria modulate $C$. difficile in ways that could affect the infection and resultant disease.

A myriad of studies have explored the relationship between the microbiome and CDI disease. Studies examining difference in disease often use different $C$. difficile strains or ribotypes in mice with similar microbiota as a proxy for variation in disease, such as strain 630 for non-severe and RT027 for severe $(19,28,29,48)$. Studies have also demonstrated variation in infection through tapering antibiotic dosage $(20,24,49)$ or by reducing the amount of $C$. difficile cells or spores used for the challenge $(19,49)$. These studies often either lack variation in the initial microbiome or have variation in the $C$. difficile infection itself, confounding any association between variation in severity and the microbiome. Recent studies have shown variation in the initial microbiome, via different murine colonies or colonizing germ-free mice with human feces, that were challenged with $C$. difficile resulted in varied outcomes of the infection $(14,15)$.

Our data have demonstrated gut bacterial relative abundances associate with variation in toxin production, histopathologic scoring of the cecal tissue and mortality. This analysis revealed populations of Akkermansia, Anaerostipes, Coprobacillus, Enterocloster, Lactonifactor, and Monoglobus were more abundant in the microbiome of non-moribund 
mice which had low histopathologic scores and no detected toxin. The protective role of these genera are supported by previous studies. Coprobacillus, Lactonifactor, and Monoglobus have been shown to be involved in dietary fiber fermentation and associated with healthy communities (50-53). Anaerostipes and Coprobacillus, which produce short chain fatty acids, have been associated with healthy communities (54-56). Furthermore, Coprobacillus, which was abundant in mice with low histopathologic scores but rare in all other mice, has been shown to contain a putative type I lantibiotic gene cluster and inhibit C. difficile colonization (57-59). Akkermansia and Enterocloster were also identified as more abundant in mice which had a low histopathologic scores but have contradictory supporting evidence in the current literature. In our data, Akkermansia was most abundant in the non-moribund mice with low histopathologic scores but there were some moribund mice which had increased populations of Akkermansia. This could be attributed to either a more protective mucus layer was present inhibiting colonization $(59,60)$ or mucus consumption by Akkermansia could have been crossfeeding $C$. difficile or exposing a niche for C. difficile (61-63). Similarly, Enterocloster was more abundant and associated with low histopathologic scores. It has been associated with healthy populations and has been used to mono-colonize germ-free mice to reduce the ability of $C$. difficile to colonize $(64,65)$. However, Enterocloster has also been involved in infections, such as bacteremia $(66,67)$. These data have exemplified populations of bacteria that have the potential to be either protective or harmful. Thus, the disease outcome is not likely based on the abundance of individual populations of bacteria, rather it is the result of the interactions of the community.

The groups of bacteria that were associated with either a higher histopathologic score or moribundity are members of the indigenous gut community that also have been associated with disease, often referred to as opportunistic pathogens. Many of the populations with pathogenic potential that associated with worse outcomes are also facultative anaerobes. Enterococcus, Klebsiella, Shigella/Escherichia, Staphylococcus, 
and Streptococcus have been shown to expand after antibiotic use $(17,68,69)$ and are commonly detected in CDI cases (70-73). In addition to these populations, Eggerthella, Prevotellaceae and Helicobacter, which associated with worse outcomes, have also been associated with intestinal inflammation (74-76). Recently, Helicobacter hepaticus was shown to be sufficient to cause susceptibility to CDI in IL-10 deficient C57BL/6 mice (77). In our experiments, when Helicobacter was present, the infection resulted in a high histopathologic score (Figure 4C). While we did not use IL-10 deficient mice, it is possible the bacterial community or host response are similarly modified by Helicobacter, allowing C. difficile infection and host damage. Aside from Helicobacter, these groups of bacteria that associated with more severe outcomes did not have a conserved association between their relative abundance and the disease severity across all mice.

Since we observed groups of bacteria that were associated with less severe disease it may be appropriate to apply the damage-response framework for microbial pathogenesis to $\operatorname{CDI}(78,79)$. This framework posits that disease is not driven by a single entity, rather it is an emergent property of the responses of the host immune system, infecting microbe, $C$. difficile, and the indigenous microbes at the site of infection. In the first set of experiments, we used the same host background, $\mathrm{C} 57 \mathrm{BL} / 6$ mice, the same infecting microbe, $C$. difficile RT027 clinical isolate 431, with different gut bacterial communities. The bacterial groups in those communities were often present in both moribund and non-moribund and across the range of histopathologic scores. Thus, it was not merely the presence of the bacteria but their activity in response to the other microbes and host which affect the extent of the host damage. Additionally, while each mouse and $C$. difficile population had the same genetic background, they too were reacting to the specific microbial community. Disease severity is driven by the cumulative effect of the host immune response and the activity of C. difficile and the gut bacteria. C. difficile drives host damage through the production of toxin. The gut microbiota can modulate host damage through the balance of metabolic and competitive interactions with $C$. difficile, such as bacteriocin production or mucin 
degradation, and interactions with the host, such as host mucus glycosylation or intestinal IL-33 expression $(14,80)$. For example, low levels of mucin degradation can provide nutrients to other community members producing a diverse non-damaging community (81). However, if mucin degradation becomes too great it reduces the protective function of the mucin layer and exposes the epithelial cells. This over-harvesting can contribute to the host damage due to other members producing toxin. Thus, the resultant intestinal damage is the balance of all activities in the gut environment. Host damage is the emergent property of numerous damage-response curves, such as one for host immune response, one for C. difficile activity and another for microbiome community activity, each of which are a composite curve of the individual activities from each group, such as antibody production, neutrophil infiltration, toxin production, sporulation, fiber and mucin degradation. Therefore, while we have identified populations of interest, it may be necessary to target multiple types of bacteria to reduce the community interactions contributing to host damage.

Here we have shown several bacterial groups and their relative abundances associated with variation in CDI disease severity. Further understanding how the microbiome affects severity in patients could reduce the amount of adverse CDI outcomes. When a patient is diagnosed with CDI, the gut community composition, in addition to the traditionally obtained clinical information, may improve our severity prediction and guide prophylactic treatment. Treating the microbiome at the time of diagnosis, in addition to $C$. difficile, may prevent the infection from becoming more severe.

\section{Materials and Methods}

Animal care. 6- to 13-week old male and female germ-free C57BL/6 were obtained from a single breeding colony in the University of Michigan Germ-free Mouse Core. Mice (N1 $n=11, N 2 n=7, N 3 n=3$, N4 $n=3$, N5 $n=3, N 6 n=3, N 7 n=7, N 8 n=3, N 9 n=2, M 1 n=3, M 2$ $n=3, M 3 n=3, M 4 n=3, M 5 n=7, M 6 n=3$ ) were housed in cages of 2-4 mice per cage and 
maintained in germ-free isolators at the University of Michigan germ-free facility. All mouse experiments were approved by the University Committee on Use and Care of Animals at the University of Michigan.

C. difficile experiments. Human fecal samples were obtained as part of Schubert et al. and selected based on community clusters (17) to result in diverse community structures. Feces were homogenized by mixing $200 \mathrm{mg}$ of sample with $5 \mathrm{ml}$ of PBS. Mice were inoculated with $100 \mu \mathrm{l}$ of the fecal homogenate via oral gavage. Two weeks after the fecal community inoculation, mice were challenged with $C$. difficile. C. difficile clinical isolate 431 came from Carlson et al. which had previously been isolated and characterized $(34,35)$ and has recently been further characterized (36). Spores concentration were determined both before and after challenge (82). $10^{3} \mathrm{C}$. difficile spores were given to each mouse via oral gavage.

Sample collection. Fecal samples were collected on the day of $C$. difficile challenge and the following 10 days. Each day, a fecal sample was collected and a portion was weighed for plating (approximately $30 \mathrm{mg}$ ) and the remaining sample was frozen at $-20^{\circ} \mathrm{C}$. Anaerobically, the weighed fecal samples were serially diluted in PBS, plated on TCCFA plates, and incubated at $37^{\circ} \mathrm{C}$ for 24 hours. The plates were then counted for the number of colony forming units (CFU) (83).

DNA sequencing. From the frozen fecal samples, total bacterial DNA was extracted using MOBIO PowerSoil-htp 96-well soil DNA isolation kit. We amplified the 16S rRNA gene V4 region and sequenced the resulting amplicons using an Illumina MiSeq as described previously (84).

Sequence curation. Sequences were processed with mothur(v.1.44.3) as previously described $(84,85)$. In short, we used a $3 \%$ dissimilarity cutoff to group sequences into operational taxonomic units (OTUs). We used a naive Bayesian classifier with the 
Ribosomal Database Project training set (version 18) to assign taxonomic classifications to each OTU (86). We sequenced a mock community of a known community composition and 16s rRNA gene sequences. We processed this mock community with our samples to calculate the error rate for our sequence curation, which was an error rate of $0.19 \%$.

Toxin cytotoxicity assay. To prepare the sample for the activity assay, fecal material was diluted 1:10 weight per volume using sterile PBS and then filter sterilized through a $0.22-\mu \mathrm{m}$ filter. Toxin activity was assessed using a Vero cell rounding-based cytotoxicity assay as described previously (29). The cytotoxicity titer was determined for each sample as the last dilution, which resulted in at least $80 \%$ cell rounding. Toxin titers are reported as the $\log 10$ of the reciprocal of the cytotoxicity titer.

Histopathology evaluation. Mouse cecal tissue was placed in histopathology cassettes and fixed in $10 \%$ formalin, then stored in $70 \%$ ethanol. McClinchey Histology Labs, Inc. (Stockbridge, MI) embedded the samples in paraffin, sectioned, and created the hematoxylin and eosin-stained slides. The slides were scored using previously described criteria by a board-certified veterinary pathologist who was blinded to the experimental groups (29). Slides were scored as 0-4 for parameters of epithelial damage, tissue edema, and inflammation and a summary score of $0-12$ was generated by summing the three individual parameter scores.

Statistical analysis and modeling. To compare community structures, we calculated Yue and Clayton dissimilarity matrices $\left(\theta_{\mathrm{YC}}\right)$ in mothur (87). We rarefied samples to 2,107 sequences per sample to limit uneven sampling biases. We tested for differences in individual taxonomic groups that would explain the outcome differences with LEfSe (88) in mothur. Remaining statistical analysis and data visualization was performed in $\mathrm{R}$ (v4.0.5) with the tidyverse package (v1.3.1). We tested for significant differences in $\beta$-diversity $\left(\theta_{Y C}\right)$ using the Wilcoxon rank sum test. We used Spearman's correlation to identify which OTUs that had a correlation between their relative abundance and the histopathologic 
summary score. $P$ values were then corrected for multiple comparisons with a Benjamini and Hochberg adjustment for a type I error rate of 0.05 (89). We built random forest models using the mikropml package (90) with relative abundance summed by taxonomic ranks from day 0 samples using mtry values of 1 through $10,15,20,25,40,50,100$. The split for training and testing varied by model to avoid overfitting the data. To determine the optimal split, we tested splits $(50 \%, 60 \%, 70 \%, 80 \%, 90 \%$ data used for training) to find the greatest portion of data that could be used to train the model while still maintaining the same performance for the training model as the model with the held-out test data. The toxin and moribundity models were trained with $60 \%$ of the data. The histopathologic score model was trained with $80 \%$ of the data. Lastly, we did not compare murine communities to donor community or clinical data because germ-free mice colonized with non-murine fecal communities have been shown to more closely resemble the murine communities than the donor species community (91). Furthermore, it is not our intention to make any inferences regarding human associated bacteria and their relationship with human CDI outcome.

Code availability. Scripts necessary to reproduce our analysis and this paper are available in an online repository (https://github.com/SchlossLab/Lesniak_Severity_XXXX_2022).

Sequence data accession number. All 16S rRNA gene sequence data and associated metadata are available through the Sequence Read Archive via accession PRJNA787941.

\section{Acknowledgements}

Thank you to Sarah Lucas and Sarah Tomkovich for critical discussion in the development and execution of this project. We also thank the University of Michigan Germ-free Mouse Core for assistance with our germfree mice, funded in part by U2CDK110768. This work was supported by several grants from the National Institutes for Health R01GM099514, U19AI090871, U01Al12455, and P30DK034933. Additionally, NAL was supported by the Molecular Mechanisms of Microbial Pathogenesis training grant (NIH T32 Al007528). The 
bioRxiv preprint doi: https://doi.org/10.1101/2022.01.31.478599; this version posted February 1, 2022. The copyright holder for this preprint

(which was not certified by peer review) is the author/funder, who has granted bioRxiv a license to display the preprint in perpetuity. It is made available under aCC-BY 4.0 International license.

410 funding agencies had no role in study design, data collection and analysis, decision to ${ }_{411}$ publish, or preparation of the manuscript. 


\section{References}

1. Kelly CP, LaMont JT. 2008. Clostridium difficile more difficult than ever. New England Journal of Medicine 359:1932-1940. doi:10.1056/nejmra0707500.

2. McDonald LC, Gerding DN, Johnson S, Bakken JS, Carroll KC, Coffin SE, Dubberke ER, Garey KW, Gould CV, Kelly C, Loo V, Sammons JS, Sandora TJ, Wilcox MH. 2018. Clinical practice guidelines for Clostridium difficile infection in adults and children: 2017 update by the infectious diseases society of america (IDSA) and society for healthcare epidemiology of america (SHEA). Clinical Infectious Diseases 66:e1-e48. doi:10.1093/cid/cix1085.

3. Perry DA, Shirley D, Micic D, Patel CP, Putler R, Menon A, Young VB, Rao K. 2021. External validation and comparison of Clostridioides difficile severity scoring systems. Clinical Infectious Diseases. doi:10.1093/cid/ciab737.

4. Britton RA, Young VB. 2014. Role of the intestinal microbiota in resistance to colonization by Clostridium difficile. Gastroenterology 146:1547-1553. doi:10.1053/j.gastro.2014.01.059.

5. Hryckowian AJ, Treuren WV, Smits SA, Davis NM, Gardner JO, Bouley DM, Sonnenburg JL. 2018. Microbiota-accessible carbohydrates suppress Clostridium difficile infection in a murine model. Nature Microbiology 3:662-669. doi:10.1038/s41564-018-0150-6.

\section{Vila AV, Collij V, Sanna S, Sinha T, Imhann F, Bourgonje AR, Mujagic Z, Jonkers} DMAE, Masclee AAM, Fu J, Kurilshikov A, Wijmenga C, Zhernakova A, Weersma RK. 2020. Impact of commonly used drugs on the composition and metabolic function of the gut microbiota. Nature Communications 11. doi:10.1038/s41467-019-14177-z.

7. Abbas A, Zackular JP. 2020. Microbe-microbe interactions during Clostridioides difficile infection. Current Opinion in Microbiology 53:19-25. doi:10.1016/j.mib.2020.01.016. 
8. Jenior ML, Leslie JL, Young VB, Schloss PD. 2017. Clostridium difficile colonizes alternative nutrient niches during infection across distinct murine gut microbiomes. mSystems 2. doi:10.1128/msystems.00063-17.

9. Sorg JA, Sonenshein AL. 2008. Bile salts and glycine as cogerminants for Clostridium difficile spores. Journal of Bacteriology 190:2505-2512. doi:10.1128/jb.01765-07.

10. Thanissery R, Winston JA, Theriot CM. 2017. Inhibition of spore germination, growth, and toxin activity of clinically relevant $C$. difficile strains by gut microbiota derived secondary bile acids. Anaerobe 45:86-100. doi:10.1016/j.anaerobe.2017.03.004.

11. Aguirre AM, Yalcinkaya N, Wu Q, Swennes A, Tessier ME, Roberts P, Miyajima F, Savidge T, Sorg JA. 2021. Bile acid-independent protection against Clostridioides difficile infection. PLOS Pathogens 17:e1010015. doi:10.1371/journal.ppat.1010015.

12. Kang JD, Myers CJ, Harris SC, Kakiyama G, Lee I-K, Yun B-S, Matsuzaki K, Furukawa M, Min H-K, Bajaj JS, Zhou H, Hylemon PB. 2019. Bile acid $7 \alpha$-dehydroxylating gut bacteria secrete antibiotics that inhibit Clostridium difficile: Role of secondary bile acids. Cell Chemical Biology 26:27-34.e4. doi:10.1016/j.chembiol.2018.10.003.

13. Leslie JL, Jenior ML, Vendrov KC, Standke AK, Barron MR, O’Brien TJ, Unverdorben L, Thaprawat P, Bergin IL, Schloss PD, Young VB. 2021. Protection from lethal Clostridioides difficile infection via intraspecies competition for cogerminant. mBio 12. doi:10.1128/mbio.00522-21.

14. Nagao-Kitamoto H, Leslie JL, Kitamoto S, Jin C, Thomsson KA, Gillilland MG, Kuffa P, Goto Y, Jenq RR, Ishii C, Hirayama A, Seekatz AM, Martens EC, Eaton KA, Kao JY, Fukuda S, Higgins PDR, Karlsson NG, Young VB, Kamada N. 2020. Interleukin-22-mediated host glycosylation prevents Clostridioides difficile infection by modulating the metabolic activity of the gut microbiota. Nature Medicine 26:608-617. 
doi:10.1038/s41591-020-0764-0.

15. Tomkovich S, Stough JMA, Bishop L, Schloss PD. 2020. The initial gut microbiota and response to antibiotic perturbation influence Clostridioides difficile clearance in mice. mSphere 5. doi:10.1128/msphere.00869-20.

16. Nagpal R, Wang S, Woods LCS, Seshie O, Chung ST, Shively CA, Register TC, Craft S, McClain DA, Yadav H. 2018. Comparative microbiome signatures and short-chain fatty acids in mouse, rat, non-human primate, and human feces. Frontiers in Microbiology 9. doi:10.3389/fmicb.2018.02897.

17. Schubert AM, Rogers MAM, Ring C, Mogle J, Petrosino JP, Young VB, Aronoff DM, Schloss PD. 2014. Microbiome data distinguish patients with Clostridium difficile infection and non-C. difficile-associated diarrhea from healthy controls. mBio 5. doi:10.1128/mbio.01021-14.

18. Gillilland MG, Erb-Downward JR, Bassis CM, Shen MC, Toews GB, Young VB, Huffnagle GB. 2012. Ecological succession of bacterial communities during conventionalization of germ-free mice. Applied and Environmental Microbiology 78:2359-2366. doi:10.1128/aem.05239-11.

19. Chen X, Katchar K, Goldsmith JD, Nanthakumar N, Cheknis A, Gerding DN, Kelly CP. 2008. A mouse model of Clostridium difficile-associated disease. Gastroenterology 135:1984-1992. doi:10.1053/j.gastro.2008.09.002.

20. Schubert AM, Sinani H, Schloss PD. 2015. Antibiotic-induced alterations of the murine gut microbiota and subsequent effects on colonization resistance against Clostridium difficile. mBio 6. doi:10.1128/mbio.00974-15.

21. Cowardin CA, Buonomo EL, Saleh MM, Wilson MG, Burgess SL, Kuehne SA, Schwan C, Eichhoff AM, Koch-Nolte F, Lyras D, Aktories K, Minton NP, Petri WA. 2016. 
The binary toxin CDT enhances Clostridium difficile virulence by suppressing protective colonic eosinophilia. Nature Microbiology 1. doi:10.1038/nmicrobiol.2016.108.

22. Seekatz AM, Rao K, Santhosh K, Young VB. 2016. Dynamics of the fecal microbiome in patients with recurrent and nonrecurrent Clostridium difficile infection. Genome Medicine 8. doi:10.1186/s13073-016-0298-8.

23. Dieterle MG, Putler R, Perry DA, Menon A, Abernathy-Close L, Perlman NS, Penkevich A, Standke A, Keidan M, Vendrov KC, Bergin IL, Young VB, Rao K. 2020. Systemic inflammatory mediators are effective biomarkers for predicting adverse outcomes in Clostridioides difficile infection. mBio 11. doi:10.1128/mbio.00180-20.

24. Lesniak NA, Schubert AM, Sinani H, Schloss PD. 2021. Clearance of Clostridioides difficile colonization is associated with antibiotic-specific bacterial changes. mSphere 6 . doi:10.1128/msphere.01238-20.

25. Lungulescu OA, Cao W, Gatskevich E, TIhabano L, Stratidis JG. 2011. CSI: A severity index for Clostridium difficile infection at the time of admission. Journal of Hospital Infection 79:151-154. doi:10.1016/j.jhin.2011.04.017.

26. Zar FA, Bakkanagari SR, Moorthi KMLST, Davis MB. 2007. A comparison of vancomycin and metronidazole for the treatment of Clostridium difficile-associated diarrhea, stratified by disease severity. Clinical Infectious Diseases 45:302-307. doi:10.1086/519265.

27. Masi A di, Leboffe L, Polticelli F, Tonon F, Zennaro C, Caterino M, Stano P, Fischer S, Hägele M, Müller M, Kleger A, Papatheodorou P, Nocca G, Arcovito A, Gori A, Ruoppolo M, Barth H, Petrosillo N, Ascenzi P, Bella SD. 2018. Human serum albumin is an essential component of the host defense mechanism against Clostridium difficile intoxication. The Journal of Infectious Diseases 218:1424-1435. doi:10.1093/infdis/jiy338. 


\section{Abernathy-Close L, Dieterle MG, Vendrov KC, Bergin IL, Rao K, Young VB.} 2020. Aging dampens the intestinal innate immune response during severe Clostridioides difficile infection and is associated with altered cytokine levels and granulocyte mobilization. Infection and Immunity 88. doi:10.1128/iai.00960-19.

29. Theriot CM, Koumpouras CC, Carlson PE, Bergin II, Aronoff DM, Young VB. 2011. Cefoperazone-treated mice as an experimental platform to assess differential virulence of Clostridium difficile strains. Gut Microbes 2:326-334. doi:10.4161/gmic.19142.

30. Goorhuis A, Bakker D, Corver J, Debast SB, Harmanus C, Notermans DW, Bergwerff AA, Dekker FW, Kuijper EJ. 2008. Emergence of Clostridium difficile infection due to a new hypervirulent strain, polymerase chain reaction ribotype 078 . Clinical Infectious Diseases 47:1162-1170. doi:10.1086/592257.

31. O'Connor JR, Johnson S, Gerding DN. 2009. Clostridium difficile infection caused by the epidemic BI/NAP1/027 strain. Gastroenterology 136:1913-1924. doi:10.1053/j.gastro.2009.02.073.

32. Rao K, Micic D, Natarajan M, Winters S, Kiel MJ, Walk ST, Santhosh K, Mogle JA, Galecki AT, LeBar W, Higgins PDR, Young VB, Aronoff DM. 2015. Clostridium difficile ribotype 027: Relationship to age, detectability of toxins A or B in stool with rapid testing, severe infection, and mortality. Clinical Infectious Diseases 61:233-241. doi:10.1093/cid/civ254.

33. Walk ST, Micic D, Jain R, Lo ES, Trivedi I, Liu EW, Almassalha LM, Ewing SA, Ring C, Galecki AT, Rogers MAM, Washer L, Newton DW, Malani PN, Young VB, Aronoff DM. 2012. Clostridium difficile ribotype does not predict severe infection. Clinical Infectious Diseases 55:1661-1668. doi:10.1093/cid/cis786.

34. Carlson PE, Walk ST, Bourgis AET, Liu MW, Kopliku F, Lo E, Young VB, 
Aronoff DM, Hanna PC. 2013. The relationship between phenotype, ribotype, and clinical disease in human Clostridium difficile isolates. Anaerobe 24:109-116. doi:10.1016/j.anaerobe.2013.04.003.

\section{Carlson PE, Kaiser AM, McColm SA, Bauer JM, Young VB, Aronoff DM, Hanna} PC. 2015. Variation in germination of Clostridium difficile clinical isolates correlates to disease severity. Anaerobe 33:64-70. doi:10.1016/j.anaerobe.2015.02.003.

36. Saund K, Pirani A, Lacy B, Hanna PC, Snitkin ES. 2021. Strain variation in Clostridioides difficile toxin activity associated with genomic variation at both PaLoc and non-PaLoc loci. doi:10.1101/2021.12.08.471880.

37. He M, Sebaihia M, Lawley TD, Stabler RA, Dawson LF, Martin MJ, Holt KE, Seth-Smith HMB, Quail MA, Rance R, Brooks K, Churcher C, Harris D, Bentley SD, Burrows C, Clark L, Corton C, Murray V, Rose G, Thurston S, Tonder A van, Walker D, Wren BW, Dougan G, Parkhill J. 2010. Evolutionary dynamics of Clostridium difficile over short and long time scales. Proceedings of the National Academy of Sciences 107:7527-7532. doi:10.1073/pnas.0914322107.

\section{Butt E, Foster JA, Keedwell E, Bell JE, Titball RW, Bhangu A, Michell SL, Sheridan}

R. 2013. Derivation and validation of a simple, accurate and robust prediction rule for risk of mortality in patients with Clostridium difficile infection. BMC Infectious Diseases 13. doi:10.1186/1471-2334-13-316.

39. Beurden YH van, Hensgens MPM, Dekkers OM, Cessie SL, Mulder CJJ, Vandenbroucke-Grauls CMJE. 2017. External validation of three prediction tools for patients at risk of a complicated course of Clostridium difficile infection: Disappointing in an outbreak setting. Infection Control \& Hospital Epidemiology 38:897-905. doi:10.1017/ice.2017.89. 
40. Jenior ML, Leslie JL, Young VB, Schloss PD. 2018. Clostridium difficile alters the structure and metabolism of distinct cecal microbiomes during initial infection to promote sustained colonization. mSphere 3. doi:10.1128/msphere.00261-18.

41. Staley C, Weingarden AR, Khoruts A, Sadowsky MJ. 2016. Interaction of gut microbiota with bile acid metabolism and its influence on disease states. Applied Microbiology and Biotechnology 101:47-64. doi:10.1007/s00253-016-8006-6.

42. Long SL, Gahan CGM, Joyce SA. 2017. Interactions between gut bacteria and bile in health and disease. Molecular Aspects of Medicine 56:54-65. doi:10.1016/j.mam.2017.06.002.

43. Sorg JA, Sonenshein AL. 2010. Inhibiting the initiation of Clostridium difficile spore germination using analogs of chenodeoxycholic acid, a bile acid. Journal of Bacteriology 192:4983-4990. doi:10.1128/jb.00610-10.

44. Dubois T, Tremblay YDN, Hamiot A, Martin-Verstraete I, Deschamps J, Monot M, Briandet R, Dupuy B. 2019. A microbiota-generated bile salt induces biofilm formation in Clostridium difficile. npj Biofilms and Microbiomes 5. doi:10.1038/s41522-019-0087-4.

\section{Ng KM, Ferreyra JA, Higginbottom SK, Lynch JB, Kashyap PC, Gopinath S, Naidu} N, Choudhury B, Weimer BC, Monack DM, Sonnenburg JL. 2013. Microbiota-liberated host sugars facilitate post-antibiotic expansion of enteric pathogens. Nature 502:96-99. doi:10.1038/nature12503.

46. Ferreyra JA, Wu KJ, Hryckowian AJ, Bouley DM, Weimer BC, Sonnenburg JL. 2014. Gut microbiota-produced succinate promotes C. difficile infection after antibiotic treatment or motility disturbance. Cell Host \& Microbe 16:770-777. doi:10.1016/j.chom.2014.11.003.

47. Martin-Verstraete I, Peltier J, Dupuy B. 2016. The regulatory networks that control Clostridium difficile toxin synthesis. Toxins 8:153. doi:10.3390/toxins8050153. 
48. Lawley TD, Clare S, Walker AW, Stares MD, Connor TR, Raisen C, Goulding D, Rad R, Schreiber F, Brandt C, Deakin LJ, Pickard DJ, Duncan SH, Flint HJ, Clark TG, Parkhill J, Dougan G. 2012. Targeted restoration of the intestinal microbiota with a simple, defined bacteriotherapy resolves relapsing Clostridium difficile disease in mice. PLoS Pathogens 8:e1002995. doi:10.1371/journal.ppat.1002995.

49. Reeves AE, Theriot CM, Bergin IL, Huffnagle GB, Schloss PD, Young VB. 2011. The interplay between microbiome dynamics and pathogen dynamics in a murine model of Clostridium difficile infection. Gut Microbes 2:145-158. doi:10.4161/gmic.2.3.16333.

50. Mabrok HB, Klopfleisch R, Ghanem KZ, Clavel T, Blaut M, Loh G. 2011. Lignan transformation by gut bacteria lowers tumor burden in a gnotobiotic rat model of breast cancer. Carcinogenesis 33:203-208. doi:10.1093/carcin/bgr256.

\section{Kim CC, Healey GR, Kelly WJ, Patchett ML, Jordens Z, Tannock GW, Sims IM, Bell} TJ, Hedderley D, Henrissat B, Rosendale DI. 2019. Genomic insights from Monoglobus pectinilyticus: A pectin-degrading specialist bacterium in the human colon. The ISME Journal 13:1437-1456. doi:10.1038/s41396-019-0363-6.

52. Prado SBR do, Minguzzi BT, Hoffmann C, Fabi JP. 2021. Modulation of human gut microbiota by dietary fibers from unripe and ripe papayas: Distinct polysaccharide degradation using a colonic in vitro fermentation model. Food Chemistry 348:129071. doi:10.1016/j.foodchem.2021.129071.

53. Muthuramalingam K, Singh V, Choi C, Choi SI, Kim YM, Unno T, Cho M. 2019. Dietary intervention using $(1,3) /(1,6)$ - $\beta$-glucan, a fungus-derived soluble prebiotic ameliorates high-fat diet-induced metabolic distress and alters beneficially the gut microbiota in mice model. European Journal of Nutrition 59:2617-2629. doi:10.1007/s00394-019-02110-5. 
54. Han S-H, Yi J, Kim J-H, Lee S, Moon H-W. 2019. Composition of gut microbiota in patients with toxigenic Clostridioides (Clostridium) difficile: Comparison between subgroups according to clinical criteria and toxin gene load. PLOS ONE 14:e0212626. doi:10.1371/journal.pone.0212626.

55. Duncan SH, Louis $\mathbf{P}$, Flint HJ. 2004. Lactate-utilizing bacteria, isolated from human feces, that produce butyrate as a major fermentation product. Applied and Environmental Microbiology 70:5810-5817. doi:10.1128/aem.70.10.5810-5817.2004.

56. Ye J, Lv L, Wu W, Li Y, Shi D, Fang D, Guo F, Jiang H, Yan R, Ye W, Li L. 2018. Butyrate protects mice against methionine-choline-deficient diet-induced non-alcoholic steatohepatitis by improving gut barrier function, attenuating inflammation and reducing endotoxin levels. Frontiers in Microbiology 9. doi:10.3389/fmicb.2018.01967.

57. Walsh CJ, Guinane CM, O'Toole PW, Cotter PD. 2017. A profile hidden markov model to investigate the distribution and frequency of LanB-encoding lantibiotic modification genes in the human oral and gut microbiome. PeerJ 5:e3254. doi:10.7717/peerj.3254.

58. Sandiford SK. 2018. Current developments in lantibiotic discovery for treating Clostridium difficile infection. Expert Opinion on Drug Discovery 14:71-79. doi:10.1080/17460441.2019.1549032.

59. Stein RR, Bucci V, Toussaint NC, Buffie CG, Rätsch G, Pamer EG, Sander C, Xavier JB. 2013. Ecological modeling from time-series inference: Insight into dynamics and stability of intestinal microbiota. PLoS Computational Biology 9:e1003388. doi:10.1371/journal.pcbi.1003388.

60. Nakashima T, Fujii K, Seki T, Aoyama M, Azuma A, Kawasome H. 2021. Novel gut microbiota modulator, which markedly increases Akkermansia muciniphila occupancy, ameliorates experimental colitis in rats. Digestive Diseases and Sciences. 
doi:10.1007/s10620-021-07131-x.

61. Geerlings S, Kostopoulos I, Vos W de, Belzer C. 2018. Akkermansia muciniphila in the human gastrointestinal tract: When, where, and how? Microorganisms 6:75. doi:10.3390/microorganisms6030075.

62. Deng H, Yang S, Zhang Y, Qian K, Zhang Z, Liu Y, Wang Y, Bai Y, Fan H, Zhao X, Zhi F. 2018. Bacteroides fragilis prevents Clostridium difficile infection in a mouse model by restoring gut barrier and microbiome regulation. Frontiers in Microbiology 9. doi:10.3389/fmicb.2018.02976.

63. Engevik MA, Engevik AC, Engevik KA, Auchtung JM, Chang-Graham AL, Ruan W, Luna RA, Hyser JM, Spinler JK, Versalovic J. 2020. Mucin-degrading microbes release monosaccharides that chemoattract Clostridioides difficile and facilitate colonization of the human intestinal mucus layer. ACS Infectious Diseases 7:1126-1142. doi:10.1021/acsinfecdis.0c00634.

64. Reeves AE, Koenigsknecht MJ, Bergin IL, Young VB. 2012. Suppression of Clostridium difficile in the gastrointestinal tracts of germfree mice inoculated with a murine isolate from the family Lachnospiraceae. Infection and Immunity 80:3786-3794. doi:10.1128/iai.00647-12.

65. Ma L, Keng J, Cheng M, Pan H, Feng B, Hu Y, Feng T, Yang F. 2021. Gut microbiome and serum metabolome alterations associated with isolated dystonia. mSphere 6. doi:10.1128/msphere.00283-21.

66. Haas KN, Blanchard JL. 2020. Reclassification of the Clostridium clostridioforme and Clostridium sphenoides clades as Enterocloster gen. nov. And Lacrimispora gen. nov., Including reclassification of 15 taxa. International Journal of Systematic and Evolutionary Microbiology 70:23-34. doi:10.1099/ijsem.0.003698. 
67. Finegold SM, Song Y, Liu C, Hecht DW, Summanen P, Könönen E, Allen SD. 2005. Clostridium clostridioforme: A mixture of three clinically important species. European Journal of Clinical Microbiology \& Infectious Diseases 24:319-324. doi:10.1007/s10096-005-1334-6.

68. VanInsberghe D, Elsherbini JA, Varian B, Poutahidis T, Erdman S, Polz MF. 2020. Diarrhoeal events can trigger long-term Clostridium difficile colonization with recurrent blooms. Nature Microbiology 5:642-650. doi:10.1038/s41564-020-0668-2.

69. Garza-González E, Mendoza-Olazarán S, Morfin-Otero R, Ramírez-Fontes A, Rodríguez-Zulueta P, Flores-Treviño S, Bocanegra-Ibarias P, Maldonado-Garza H, Camacho-Ortiz A. 2019. Intestinal microbiome changes in fecal microbiota transplant (FMT) vs. FMT enriched with Lactobacillus in the treatment of recurrent Clostridioides difficile infection. Canadian Journal of Gastroenterology and Hepatology 2019:1-7. doi:10.1155/2019/4549298.

70. Shafiq M, Alturkmani H, Zafar Y, Mittal V, Lodhi H, Ullah W, Brewer J. 2020. Effects of co-infection on the clinical outcomes of Clostridium difficile infection. Gut Pathogens 12. doi:10.1186/s13099-020-00348-7.

71. Keith JW, Dong Q, Sorbara MT, Becattini S, Sia JK, Gjonbalaj M, Seok R, Leiner IM, Littmann ER, Pamer EG. 2020. Impact of antibiotic-resistant bacteria on immune activation and Clostridioides difficile infection in the mouse intestine. Infection and Immunity 88. doi:10.1128/iai.00362-19.

72. Zackular JP, Moore JL, Jordan AT, Juttukonda LJ, Noto MJ, Nicholson MR, Crews JD, Semler MW, Zhang Y, Ware LB, Washington MK, Chazin WJ, Caprioli RM, Skaar EP. 2016. Dietary zinc alters the microbiota and decreases resistance to Clostridium difficile infection. Nature Medicine 22:1330-1334. doi:10.1038/nm.4174. 
73. Berkell M, Mysara M, Xavier BB, Werkhoven $\mathbf{C H}$ van, Monsieurs $\mathbf{P}$, Lammens C, Ducher A, Vehreschild MJGT, Goossens H, Gunzburg J de, Bonten MJM, Malhotra-Kumar S. 2021. Microbiota-based markers predictive of development of Clostridioides difficile infection. Nature Communications 12. doi:10.1038/s41467-021-22302-0.

74. Gardiner BJ, Tai AY, Kotsanas D, Francis MJ, Roberts SA, Ballard SA, Junckerstorff RK, Korman TM. 2014. Clinical and microbiological characteristics of Eggerthella lenta bacteremia. Journal of Clinical Microbiology 53:626-635. doi:10.1128/jcm.02926-14.

75. Iljazovic A, Roy U, Gálvez EJC, Lesker TR, Zhao B, Gronow A, Amend L, Will SE, Hofmann JD, Pils MC, Schmidt-Hohagen K, Neumann-Schaal M, Strowig T. 2020. Perturbation of the gut microbiome by Prevotella spp. enhances host susceptibility to mucosal inflammation. Mucosal Immunology 14:113-124. doi:10.1038/s41385-020-0296-4.

76. Nagalingam NA, Robinson CJ, Bergin IL, Eaton KA, Huffnagle GB, Young VB. 2013. The effects of intestinal microbial community structure on disease manifestation in $\mathrm{IL}-10^{-/-}$mice infected with Helicobacter hepaticus. Microbiome 1. doi:10.1186/2049-2618-1-15.

77. Abernathy-Close L, Barron MR, George JM, Dieterle MG, Vendrov KC, Bergin IL, Young VB. 2021. Intestinal inflammation and altered gut microbiota associated with inflammatory bowel disease render mice susceptible to Clostridioides difficile colonization and infection. mBio. doi:10.1128/mbio.02733-20.

78. Pirofski L-a, Casadevall A. 2008. The damage-response framework of microbial pathogenesis and infectious diseases, pp. 135-146. In Advances in experimental medicine and biology. Springer New York. 
79. Casadevall A, Pirofski L-a. 2014. What is a host? Incorporating the microbiota into the damage-response framework. Infection and Immunity 83:2-7. doi:10.1128/iai.02627-14.

80. Frisbee AL, Saleh MM, Young MK, Leslie JL, Simpson ME, Abhyankar MM, Cowardin CA, Ma JZ, Pramoonjago P, Turner SD, Liou AP, Buonomo EL, Petri WA. 2019. IL-33 drives group 2 innate lymphoid cell-mediated protection during Clostridium difficile infection. Nature Communications 10. doi:10.1038/s41467-019-10733-9.

81. Tailford LE, Crost EH, Kavanaugh D, Juge N. 2015. Mucin glycan foraging in the human gut microbiome. Frontiers in Genetics 6. doi:10.3389/fgene.2015.00081.

82. Sorg JA, Dineen SS. 2009. Laboratory maintenance of Clostridium difficile. Current Protocols in Microbiology 12. doi:10.1002/9780471729259.mc09a01s12.

83. Winston JA, Thanissery R, Montgomery SA, Theriot CM. 2016. Cefoperazone-treated mouse model of clinically-relevant Clostridium difficile strain R20291. Journal of Visualized Experiments. doi:10.3791/54850.

84. Kozich JJ, Westcott SL, Baxter NT, Highlander SK, Schloss PD. 2013. Development of a dual-index sequencing strategy and curation pipeline for analyzing amplicon sequence data on the MiSeq illumina sequencing platform. Applied and Environmental Microbiology 79:5112-5120. doi:10.1128/aem.01043-13.

85. Schloss PD, Westcott SL, Ryabin T, Hall JR, Hartmann M, Hollister EB, Lesniewski RA, Oakley BB, Parks DH, Robinson CJ, Sahl JW, Stres B, Thallinger GG, Horn DJV, Weber CF. 2009. Introducing mothur: Open-source, platform-independent, community-supported software for describing and comparing microbial communities. Applied and Environmental Microbiology 75:7537-7541. doi:10.1128/aem.01541-09.

86. Wang Q, Garrity GM, Tiedje JM, Cole JR. 2007. Naïve bayesian classifier for rapid assignment of rRNA sequences into the new bacterial taxonomy. Applied and 
Environmental Microbiology 73:5261-5267. doi:10.1128/aem.00062-07.

87. Yue JC, Clayton MK. 2005. A similarity measure based on species proportions. Communications in Statistics - Theory and Methods 34:2123-2131. doi:10.1080/sta-200066418.

\section{Segata N, Izard J, Waldron L, Gevers D, Miropolsky L, Garrett WS, Huttenhower}

C. 2011. Metagenomic biomarker discovery and explanation. Genome Biology 12:R60. doi:10.1186/gb-2011-12-6-r60.

89. Benjamini Y, Hochberg Y. 1995. Controlling the false discovery rate: A practical and powerful approach to multiple testing. Journal of the Royal Statistical Society: Series B (Methodological) 57:289-300. doi:10.1111/j.2517-6161.1995.tb02031.x.

90. Topçuoğlu B, Lapp Z, Sovacool K, Snitkin E, Wiens J, Schloss P. 2021. Mikropml: User-friendly $\mathrm{R}$ package for supervised machine learning pipelines. Journal of Open Source Software 6:3073. doi:10.21105/joss.03073.

91. Rawls JF, Mahowald MA, Ley RE, Gordon JI. 2006. Reciprocal gut microbiota transplants from zebrafish and mice to germ-free recipients reveal host habitat selection. Cell 127:423-433. doi:10.1016/j.cell.2006.08.043. 

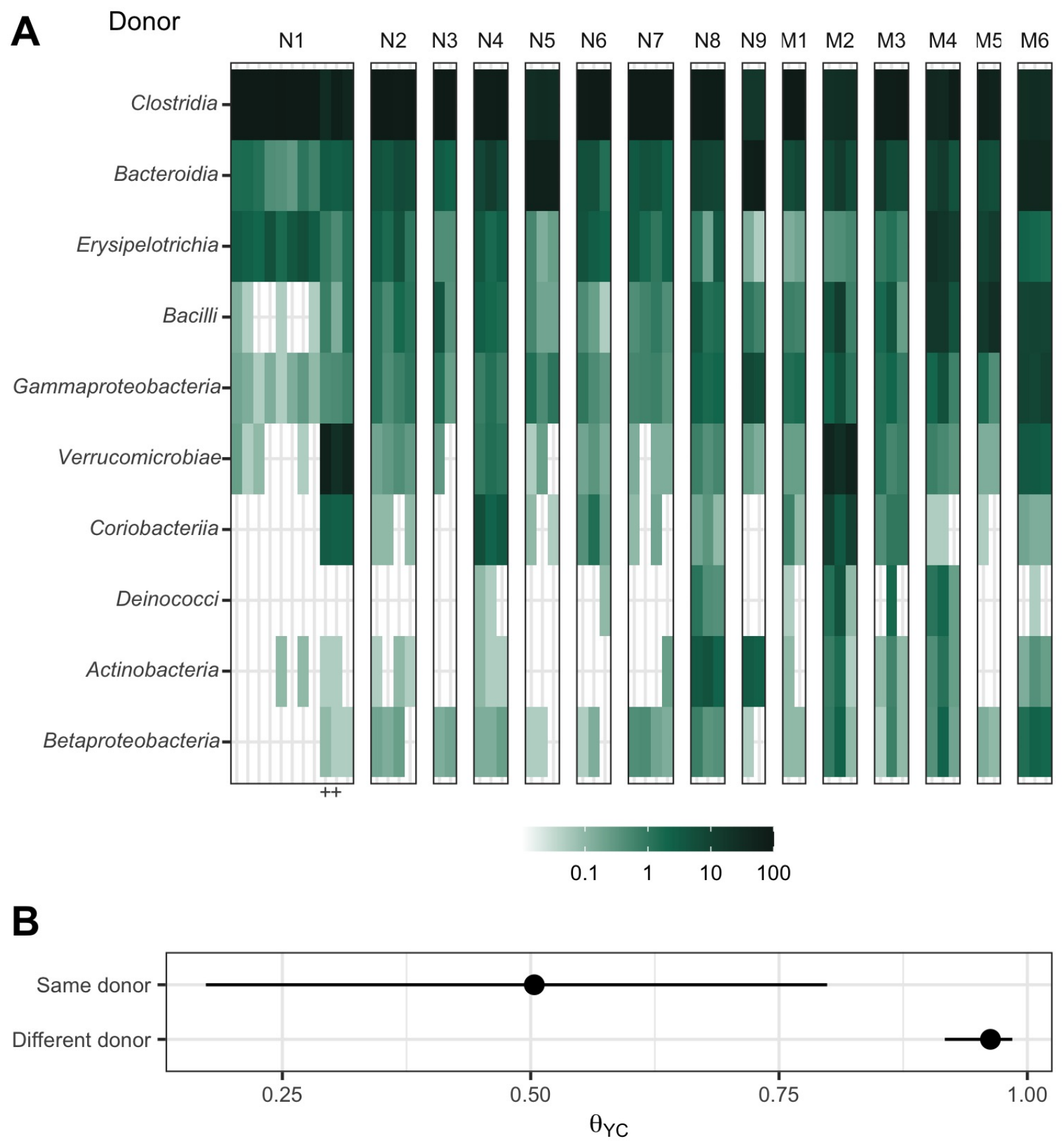

Figure 1. Human fecal microbial communities established diverse gut bacterial communities in germ-free mice. (A) Relative abundances of the 10 most abundant bacterial classes observed in the feces of previously germ-free C57BI/6 mice 14 days post-colonization with human fecal samples (i.e., day 0 relative to $C$. difficile challenge). Each column of abundances represents an individual mouse. Mice that received the same 
donor feces are grouped together and labeled above with a letter ( $\mathrm{N}$ for non-moribund mice and $\mathrm{M}$ for moribund mice) and number (ordered by mean histopathologic score of the donor group). + indicates the mice which did not have detectable $C$. difficile CFU (Figure 2). (B) Median (points) and interquartile range (lines) of $\beta$-diversity $\left(\theta_{\mathrm{YC}}\right)$ between an individual mouse and either all others which were inoculated with feces from the same donor or from a different donor. The $\beta$-diversity among the same donor comparison group was significantly less than the $\beta$-diversity of the different donor group $(P<0.05$, calculated by Wilcoxon rank sum test).

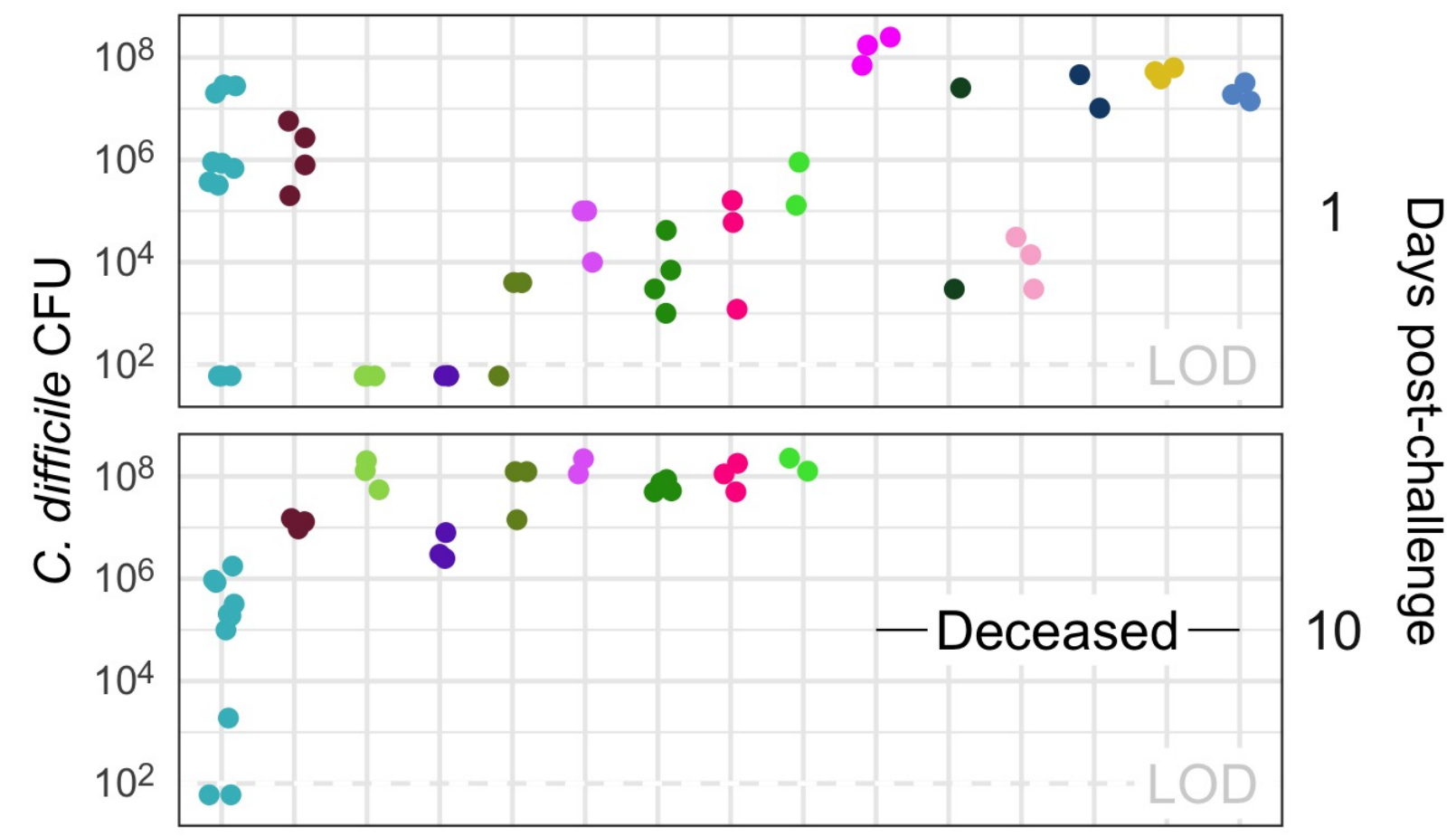

N1 N2 N3 N4 N5 N6 N7 N8 N9 M1 M2 M3 M4 M5 M6 Donor

Figure 2. All donor groups resulted in $C$. difficile infection but with different outcomes. C. difficile CFU per gram of stool was measured the day after challenge with $10^{3}$ C. difficile RT027 clinical isolate 431 spores and at the end of the experiment, 
A

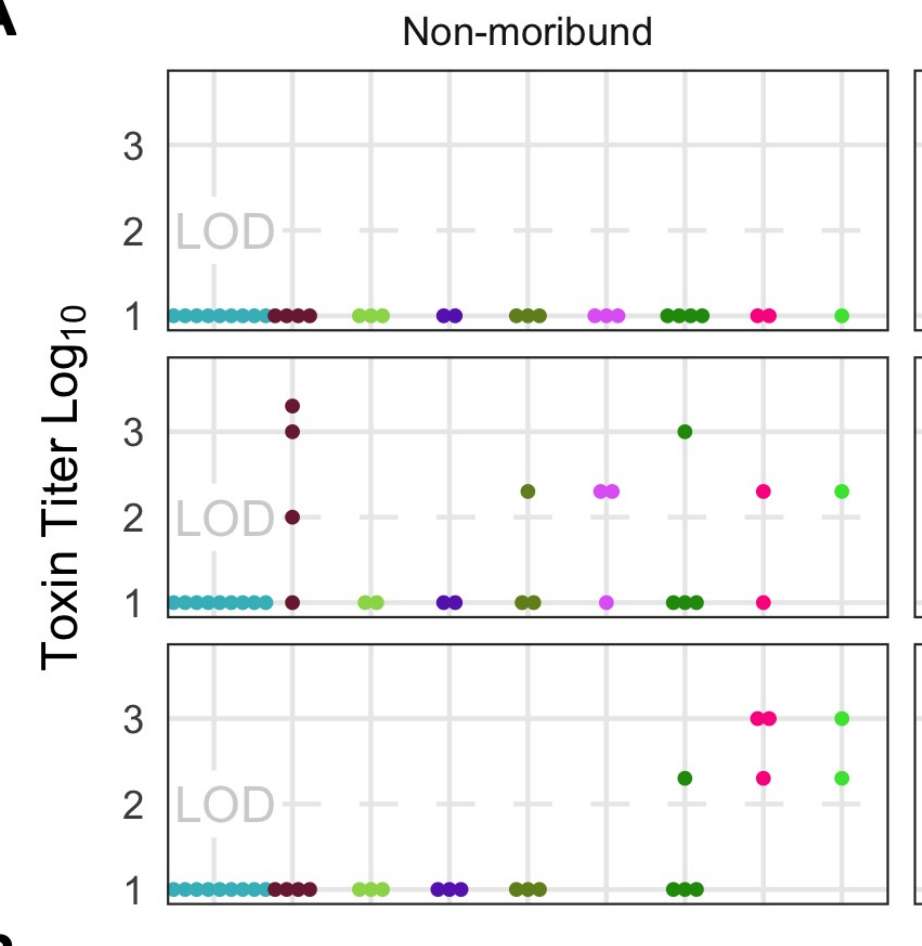

B detection.

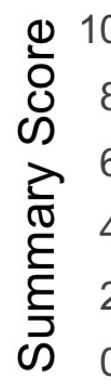

$\mathrm{N}$

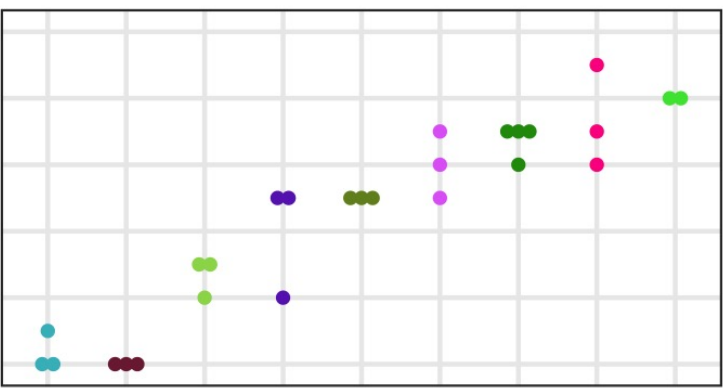

$\begin{array}{llllllllll} & \text { N } & \text { N2 } & \text { N3 } & \text { N4 } & \text { N5 } & \text { N6 } & \text { N7 } & \text { N8 } & \text { N9 }\end{array}$

10 days post-challenge. Each point represents an individual mouse. Mice are grouped by donor and labeled by the donor letter ( $\mathrm{N}$ for non-moribund mice and $\mathrm{M}$ for moribund mice) and number (ordered by mean histopathologic score of the donor group). Points are colored by donor group. Mice from donor groups N1 through N6 succumbed to the infection prior to day 10 and were not plated on day 10 post-challenge. LOD = Limit of

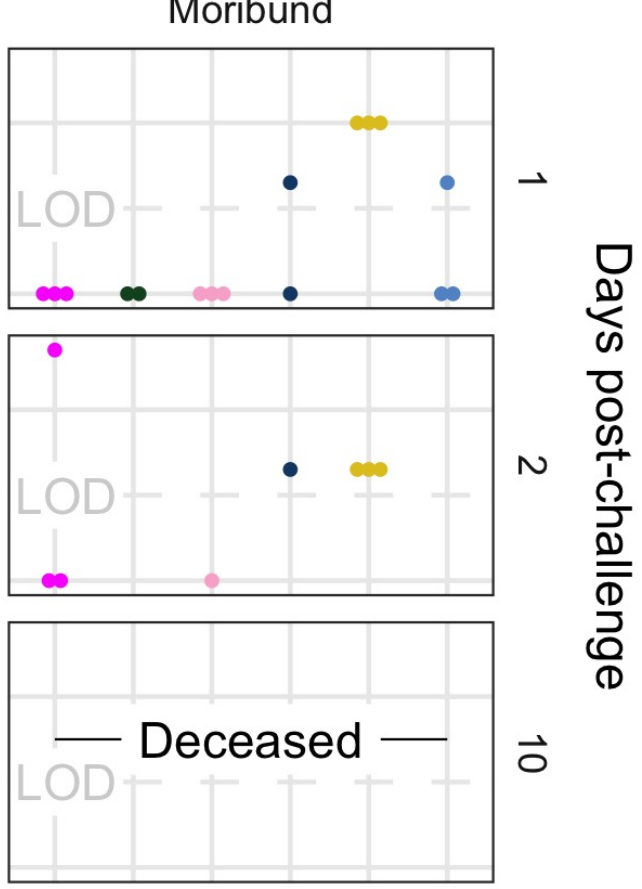

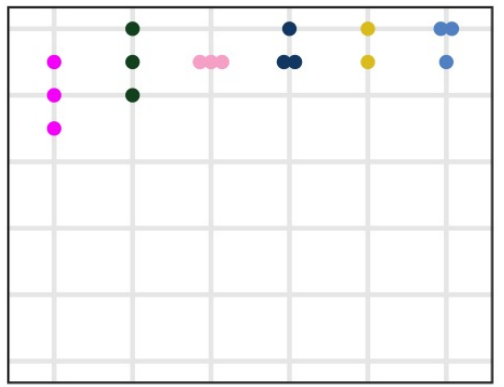

M1 M2 M3 M4 M5 M6

묵
응
을. 
Figure 3. Histopathologic score and toxin activity varied across donor groups. (A) Fecal toxin activity was detected in some mice post $C$. difficile challenge in both moribund and non-moribund mice. (B) Cecum scored for histopathologic damage from mice at the end of the experiment. Samples were collected for histopathologic scoring on day 10 post-challenge for non-moribund mice or the day the mouse succumbed to the infection for the moribund group (day 2 or 3 post-challenge). Each point represents an individual mouse. Mice are grouped by donor and labeled by the donor letter ( $\mathrm{N}$ for non-moribund mice and $\mathrm{M}$ for moribund mice) and number (ordered by mean histopathologic score of the donor group). Points are colored by donor group. Mice in group N1 that have a summary score of 0 are the mice which did not have detectable C. difficile CFU (Figure 2). Missing points are from mice that had insufficient fecal sample collected for assaying toxin or cecum for histopathologic scoring. LOD = Limit of detection. 
A

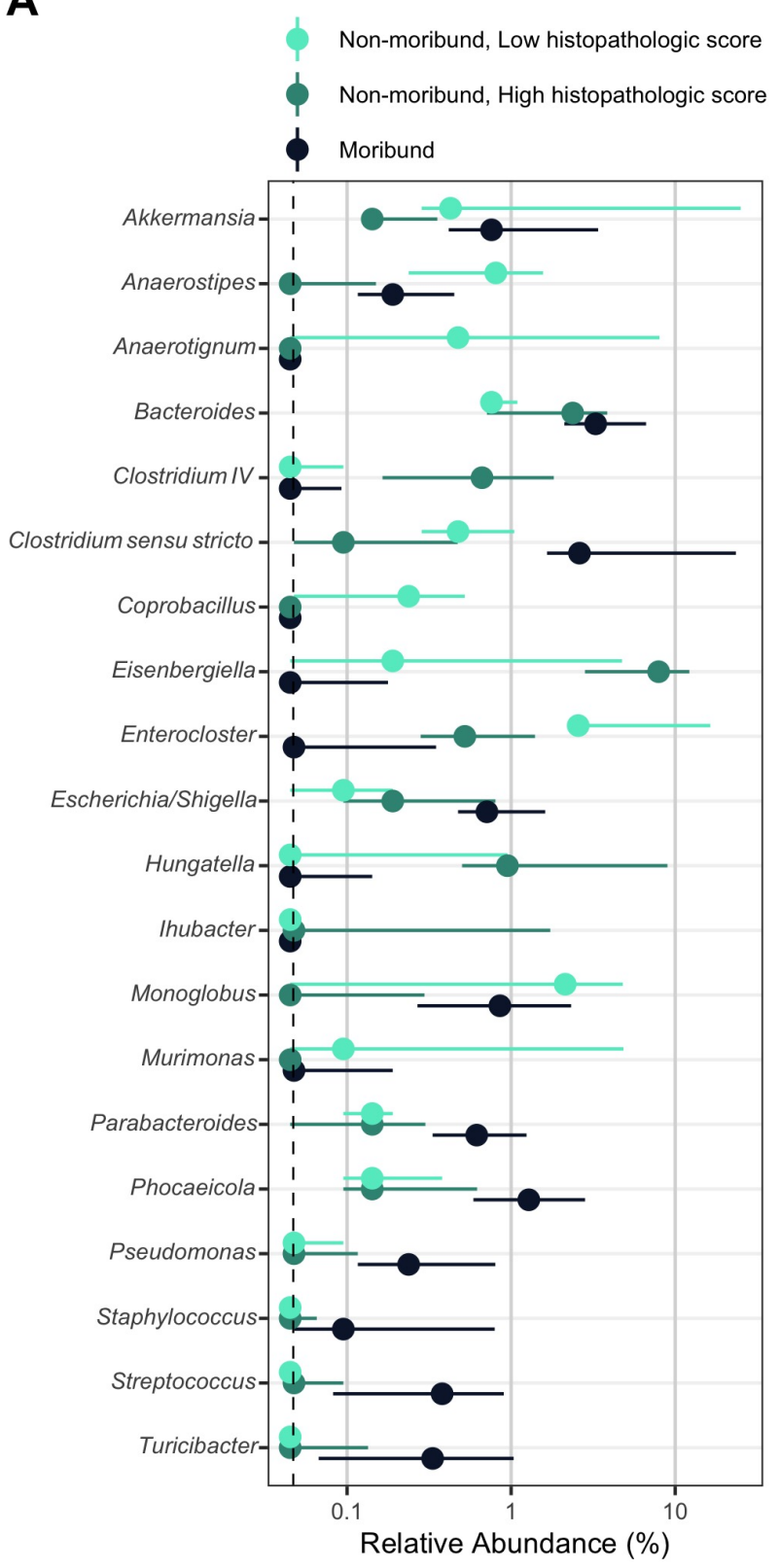

B
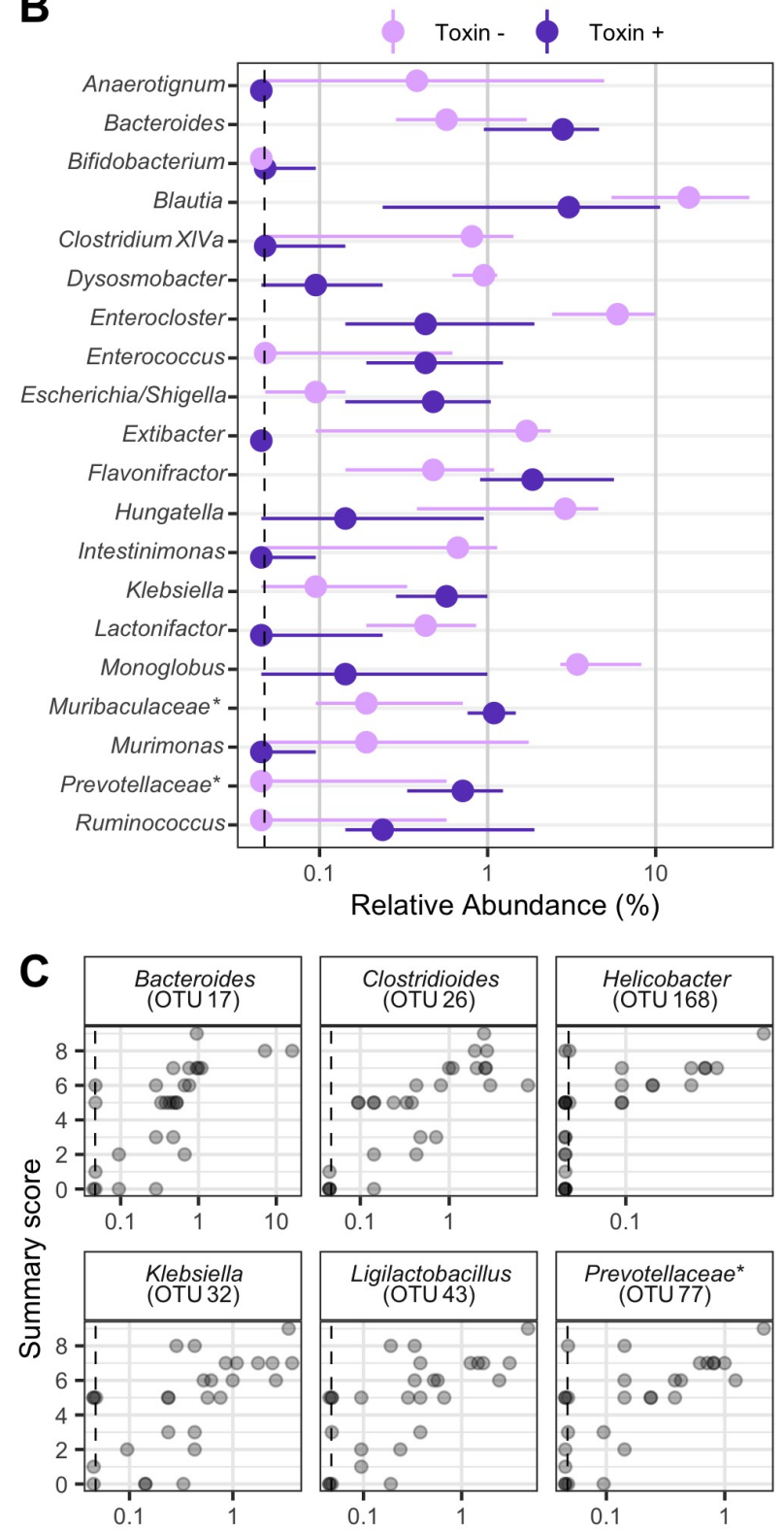

0.1

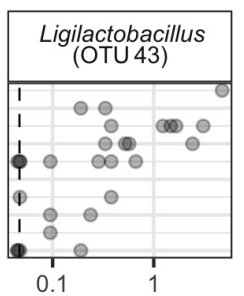

Relative Abundance (\%)

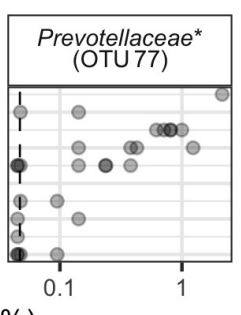

\section{Figure 4. Individual fecal bacterial community members of the murine gut associated} with $C$.difficile infection outcomes. (A and B) Relative abundance of genera at the time of $C$. difficile challenge (Day 0 ) that varied significantly by the moribundity and histopathologic summary score or detected toxin by LEfSe analysis. Median (points) and interquartile range (lines) are plotted. Genera are ordered alphabetically to ease comparisons across analyses. (A) Relative abundances were compared across infection 
outcome of moribund (colored black) or non-moribund with either a high histopathologic score (score greater than the median score of 5 , colored green) or a low histopathologic summary score (score less than the median score of 5, colored light green). (B) Relative abundances were compared between mice which toxin activity was detected (Toxin +, colored dark purple) and which no toxin activity was detected (Toxin -, colored light purple). (C) Endpoint bacterial OTUs correlated with histopathologic summary score. Each individual mouse is plotted (transparent gray point). Spearman's correlations were statistically significant after Benjamini-Hochberg correction for multiple comparisons. All bacterial groups are ordered alphabetically. * indicates that the bacterial group was unclassified at lower taxonomic classification ranks. 
bioRxiv preprint doi: https:/doi.org/10.1101/2022 0131.478599. this version posted February 12022 The copyright holder for this preprint (which was not certified by peer review) is the author/funder, who has granted bioRxiv a license to display the preprint in perpetuity. It is made available under aCC-BY 4.0 International license.

A

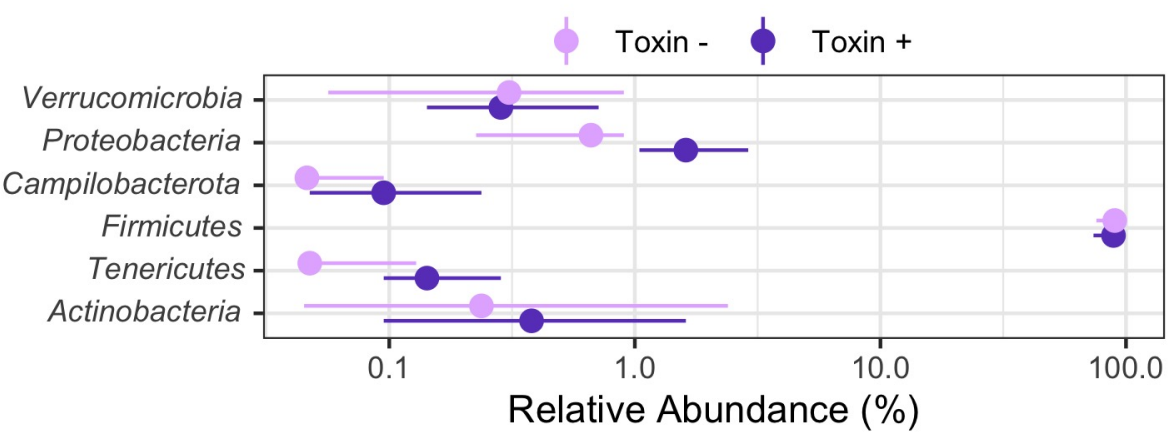

B

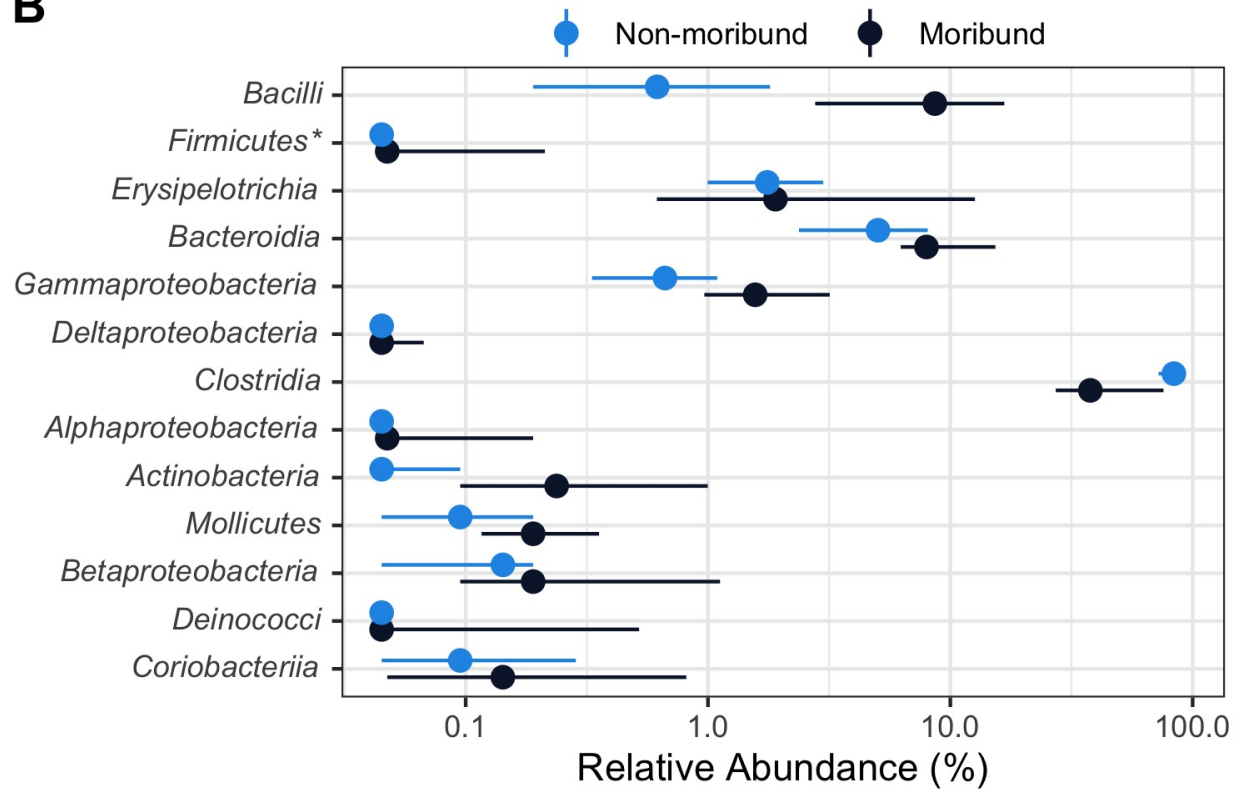

C

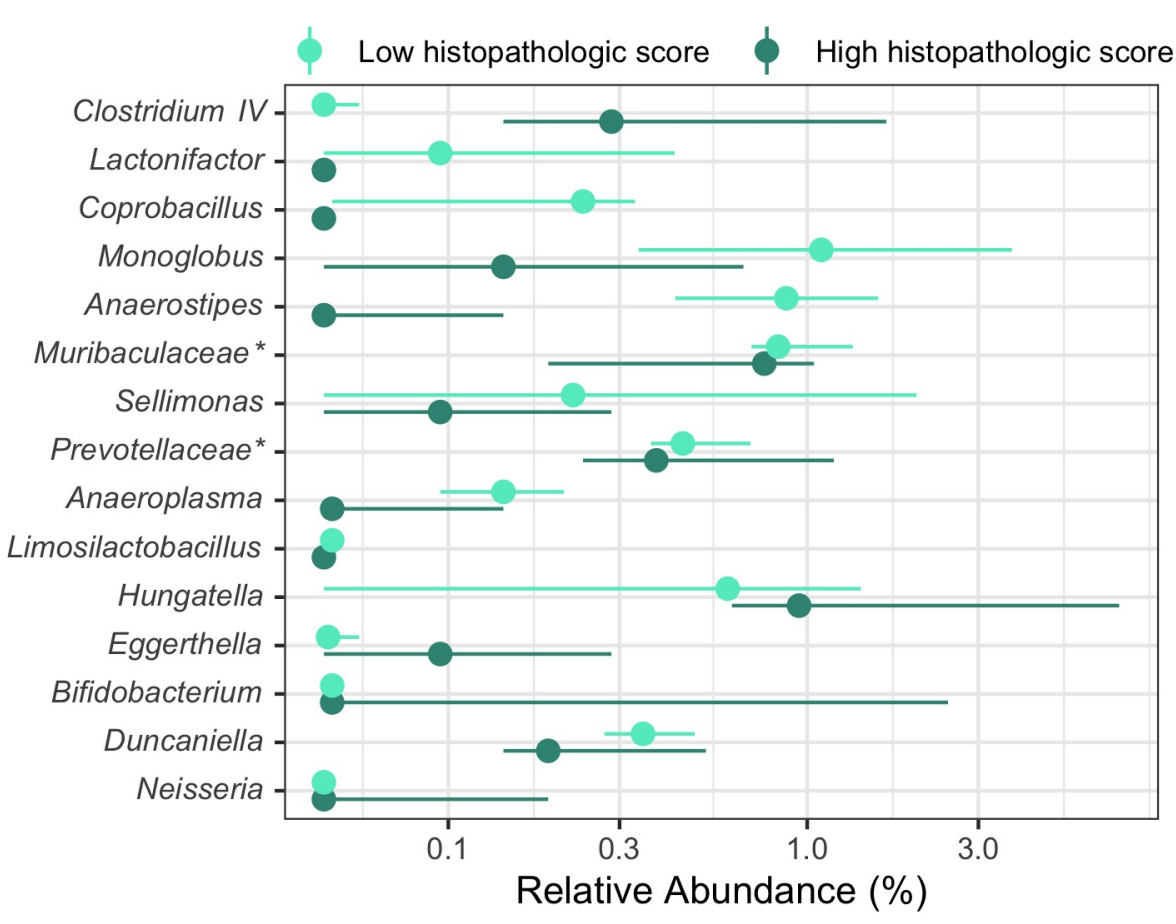


Figure 5. Fecal bacterial community members of the murine gut at the time of $C$. difficile infection predicted outcomes of the infection. On the day of infection (Day 0), bacterial community members grouped by different classification rank were modeled with random forest to predict the infection outcome. The models used the highest taxonomic classification rank that performed as well as the lower ranks. Median (solid points) and interquartile range (lines) of the group relative abundance are plotted. Bacterial groups are ordered by their importance to the model; taxonomic group at the top of the plot had the greatest decrease in performance when its relative abundances were permuted. * indicates that the bacterial group was unclassified at lower taxonomic classification ranks. (A) Bacterial members grouped by phyla predicted which mice would have toxin activity detected at any point throughout the infection (Toxin + , dark purple). (B) Bacterial members grouped by class predicted which mice would become moribund (dark blue). (C) Bacterial members grouped by genera predicted if the mice would have a high (score greater than the median score of 5 , colored dark green) or low (score less than the median score of 5 , colored light green) histopathologic summary score. 
Non-moribund
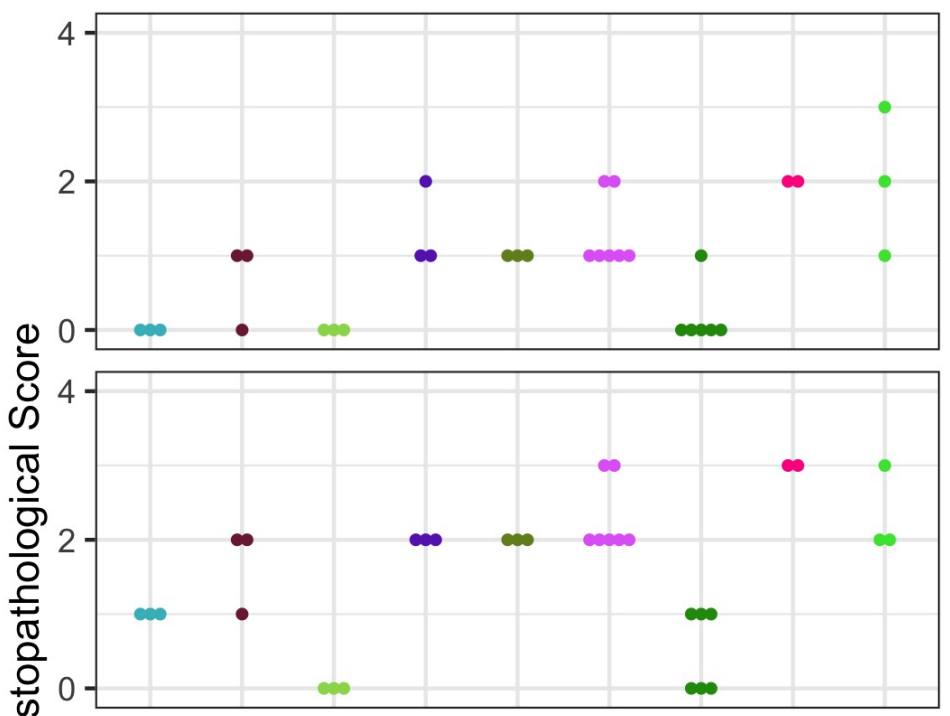

臬

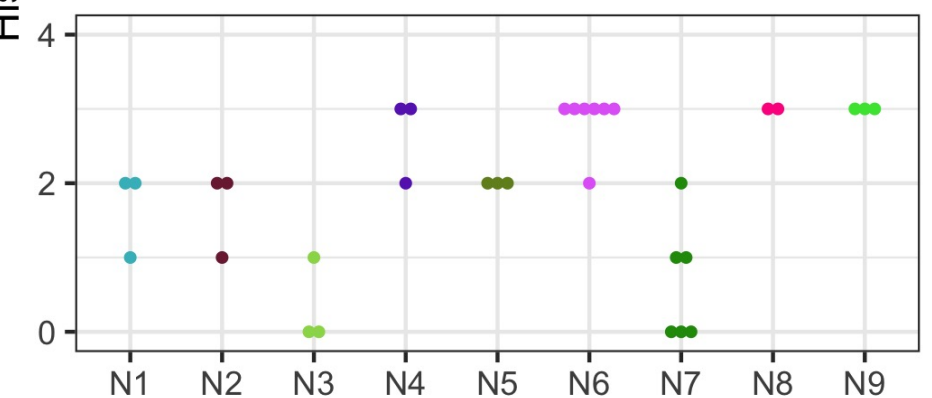

Moribund
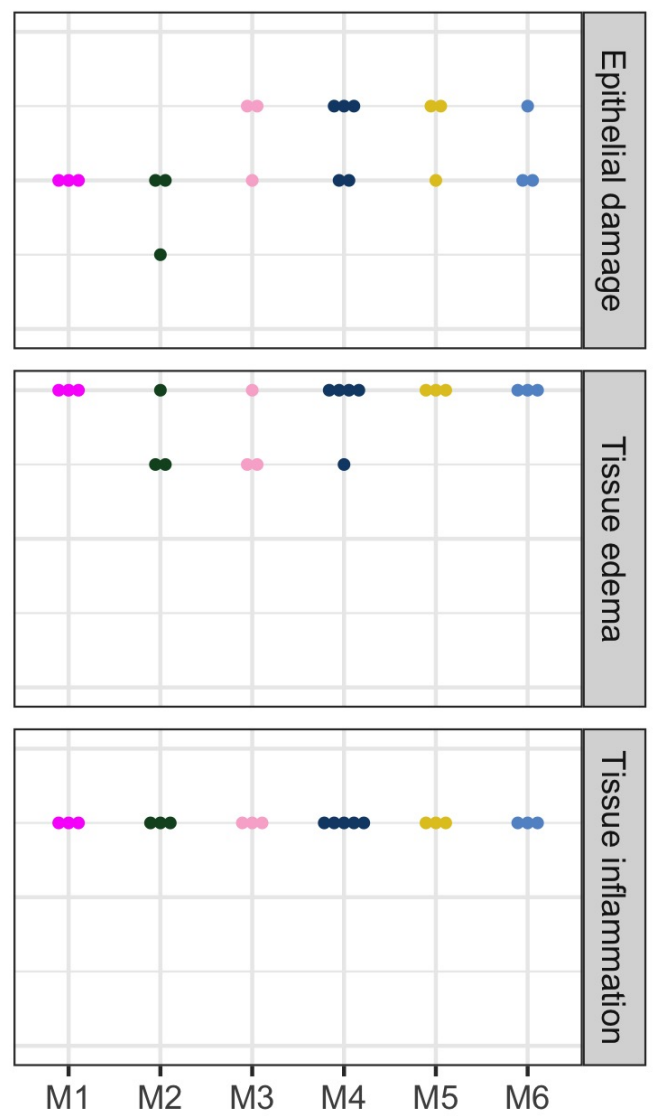

\section{Figure S1. Histopathologic score of tissue damage at the endpoint of the infection.}

Tissue collected at the endpoint, either day 10 post-challenge (Non-moribund) or day mice succumbed to infection (Moribund), were scored from histopathologic damage. Each point represents an individual mouse. Mice (points) are grouped and colored by their human fecal community donor. Missing points are from mice that had insufficient sample for histopathologic scoring. 
bioRxiv preprint doi: https://doi.org/10.1101/2022 0131.478599; this version posted February 1 2022. The copyright holder for this preprint (which was not certified by peer review) is the author/funder, who has granted bioRxiv a license to display the preprint in perpetuity. It is made available under aCC-BY 4.0 International license.

\section{Toxin activity}

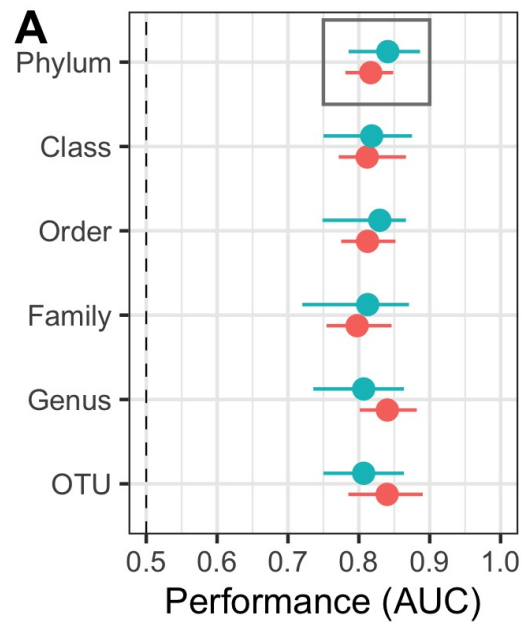

\section{Moribundity}

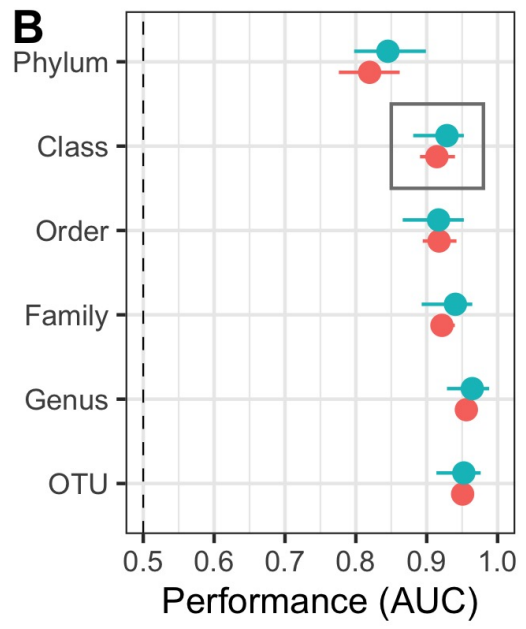

Histopathologic score

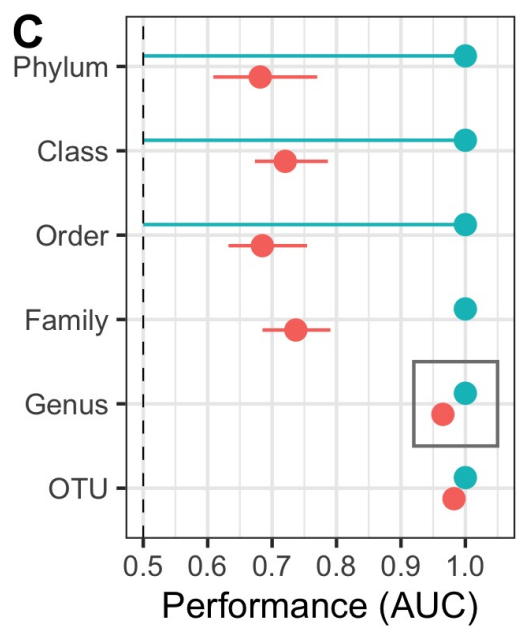

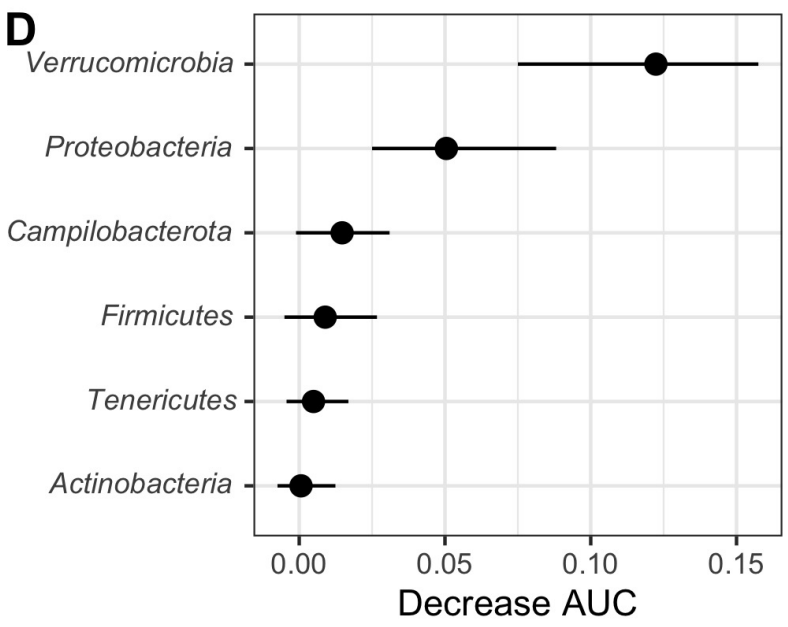
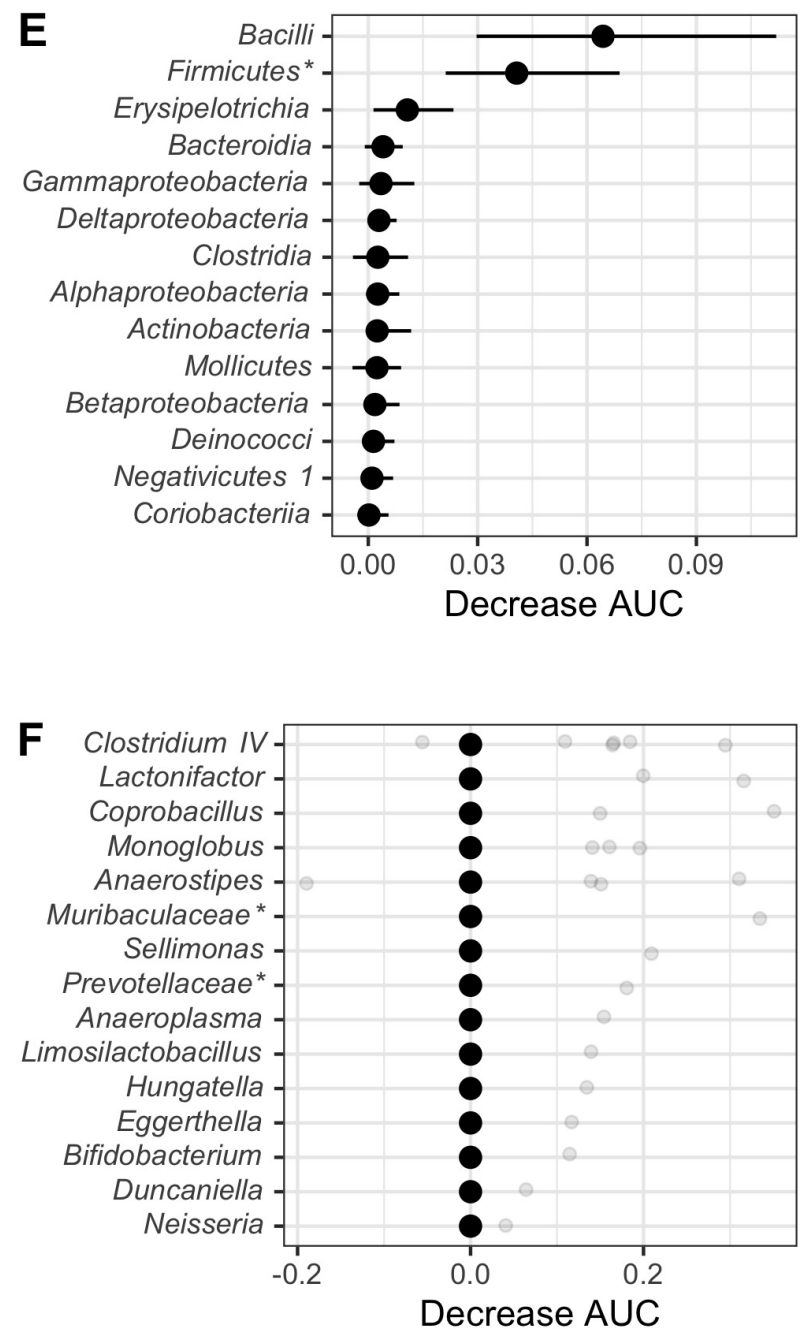

Cross Validation Test

Cross Validation Test

Cross Validation Test 
Figure S2. Random forest models predicted outcomes of the $\boldsymbol{C}$. difficile challenge. (A-C) Taxonomic classification rank model performance. Relative abundance at the time of $C$. difficile challenge (Day 0 ) of the bacterial community members grouped by different classification rank were modeled with random forest to predict the infection outcome. The models used the highest taxonomic classification rank performed as well as the lower ranks. Black rectangle highlights classification rank used to model each outcome. (D-F) Model feature importance. Bacterial groups are ordered by their decrease in area under receiver-operator curve (AUC) when its relative abundances was permuted. Individual relative abundances were added to $\mathrm{F}$ since differences in AUC were outside the interquartile range. * indicates bacterial group was unclassified at lower taxonomic classification ranks. For all plots, median (solid points) and interquartile range (lines) are plotted. (A) Toxin production modeled which mice would have toxin detected during the experiment. (B) Moribundity modeled which mice would succumb to the infection prior to day 10 post-challenge. (C) Histopathologic score modeled which mice would have a high (score greater than the median score of 5 ) or low (score less than the median score of 5) histopathologic summary score. (D) Bacterial phyla which affected the performance of predicting detectable toxin activity when permuted. (E) Bacterial classes which affected the performance of predicting moribundity when permuted. (D) Bacterial genera which affected the performance of predicting histopathologic score when permuted. 